\title{
Tensões residuais induzidas pela operação de fresamento do aço ABNT 4340 sob variação da velocidade de corte, ângulo de posição e tratamento térmico
}

\author{
Residual stresses induced by milling operations \\ of ABNT 4340 steel under variation of cutting \\ speed, edge angle and heat treatment
}

Airton de Souza ${ }^{1}$, Marcelo Araújo Câmara ${ }^{1}$

\begin{abstract}
${ }^{1}$ Programa de Pós-Graduação em Engenharia Mecânica, Universidade Federal de Minas Gerais, Av. Antônio Carlos, 6627, CEP: 31270-901, Pampulha, Belo Horizonte, MG, Brasil.

e-mail: airtonso@yahoo.com.br, marcelocamara@demec.ufmg.br
\end{abstract}

\section{RESUMO}

Dentre os diversos processos de fabricação destaca-se a usinagem. Dentre suas operações tem-se a de fresamento que, confere características à superfície gerada que influem no desempenho do componente ou peça em trabalho. Uma destas características é a tensão residual induzida pelo processo. Dependendo de seu caráter, trativo ou compressivo, intensidade e profundidade afetada, pode ser benéfica ou deletéria. Neste trabalho foi investigado o efeito dos parâmetros, velocidade de corte, ângulo de posição da fresa e condição do material, aço ABNT 4340, obtida pelos tratamentos térmicos de recozimento e normalização, sobre a tensão residual induzida na superfície. Para isto, foi realizado um planejamento fatorial $2 \times 3 \times 2$ com três réplicas. As tensões residuais foram medidas pelo método do furo central. Os resultados obtidos foram organizados e analisados sob os aspectos qualitativo, perfil ao longo da profundidade, e quantitativo. Os resultados indicaram que o aumento da velocidade de corte fez com que a tensão residual induzida na superfície fosse compressiva ou menos trativa. A variação do ângulo de posição exerceu efeito discreto sobre a tensão residual. O material fresado na condição normalizado apresentou tensões residuais compressivas enquanto que na condição recozido, trativas. Para avaliação do aspecto quantitativo foi realizada uma análise de variância para os dados referentes às tensões residuais induzidas na profundidade de $17 \mu \mathrm{m}$ abaixo da superfície. O resultado demonstrou que os dados seguem uma distribuição normal e que os fatores velocidade de corte e tratamento térmico se mostraram significativos ao nível de confiança de $95 \%$ tanto isoladamente quanto nas interações de segunda e terceira ordem.

Palavras-chave: fresamento, tensão residual, ângulo de posição, método do furo central, 4340.

\begin{abstract}
Among the various manufacturing processes, it is worth mentioning the machining. Among its operations is milling, which confers characteristics to the surface generated that influence the performance of the component or workpiece. One of these characteristics is the process-induced residual stress. Depending on its character, trative or compressive, intensity and depth affected, it can be beneficial or deleterious. This work investigated the effect of the parameters, cutting speed, edge angle and material condition, ABNT 4340 steel, obtained by annealing and normalizing heat treatments on residual stress induced on the surface. For this, a $2 \times 3 \times 2$ factorial design with three replicates was performed. The residual stresses were measured by the hole drilling method. The results obtained were organized and analyzed on the qualitative aspects, profile along the depth, and quantitative. The results indicated that the increase of cutting speed caused the residual stress induced on the surface to be compressive or less tractive. The variation of the edge angle exerted a discrete effect on the residual stress. The milled material in the normalized condition showed compressive residual stresses, on the other hand in the annealed condition trative one. In order to evaluate the quantitative aspect, a variance analysis was performed for the residual stress induced in the depth of $17 \mu \mathrm{m}$ beneath surface. The results showed that the data follow a normal distribution and that the cutting speed and heat treatment factors
\end{abstract}


were found to be significant at the $95 \%$ confidence level both in isolation and in the second and third order interactions

Keywords: milling, residual stress, edge angle, hole drilling method, 4340.

\section{INTRODUÇ̃̃O}

Com a forte demanda por produtos e serviços a competitividade se tornou cada vez mais acirrada tornando-se necessário o aprimoramento dos processos de fabricação tanto no que diz respeito a aspectos de produtividade e custos, quanto à qualidade, além do desenvolvimento de novos processos.

Dentre os diversos processos de fabricação disponíveis destaca-se a usinagem, que transforma em cavacos algo em torno de $10 \%$ de toda a produção de metais e empregando dezenas de milhões de pessoas. TRENT apud MACHADO et al. [1]. O processo de usinagem é realizado por diversas operações dentre as quais destaca-se a de fresamento, reconhecida pela versatilidade na produção de geometrias diversas, além de garantir elevadas taxas de remoção de material, visto que a ferramenta (fresa) possui múltiplas arestas de corte [1].

Todo processo de fabricação, desde o mais trivial ao mais complexo envolve uma série de fatores e particularidades que conferem ao produto final características que influem no seu desempenho, tanto no sentido de contribuir positivamente quanto negativamente. Neste sentido uma característica conferida à peça usinada em decorrência da operação de fresamento é a indução de tensões residuais na superfície obtida. Estas tensões dependendo de suas intensidades e caráter, trativo ou compressivo, podem ser benéficas ou deletérias para a peça durante o desempenho de sua função, ou comprometer operações de acabamento causando distorções dimensionais significativas. Sendo assim, torna-se importante conhecer e controlar os parâmetros que governam o processo.

Além dos parâmetros atribuídos ao processo de usinagem outra característica importante quanto à indução de tensões residuais devidas ao processo de usinagem diz respeito à condição do material no que se refere às suas propriedades tais como, dureza e microestrutura, propriedades estas que podem ser em certa medida controladas por meio de tratamentos térmicos.

Este trabalho tem por objetivo geral estudar o efeito dos parâmetros de usinagem, velocidade de corte e ângulo de posição da fresa, e da condição do material quanto ao tratamento térmico, recozido ou normalizado, sobre a tensão residual induzida na superfície obtida pela operação de fresamento de faceamento do aço ABNT 4340. Como objetivos específicos buscou-se:

1. Caracterizar o aço ABNT 4340 nas condições de recozido e normalizado para atestar sua conformidade por meio da realização de ensaio de tração para obter as propriedades mecânicas de limite de resistência a tração e alongamento percentual; realização de metalografias para identificar os principais constituintes da microestrutura; medição da macro dureza e determinação da composição química por meio de espectroscopia óptica.

2. Avaliar o efeito da condição do material, recozido ou normalizado, sobre a tensão residual induzida pela operação de fresamento do aço ABNT 4340, por meio de análise qualitativa, e quantitativa.

3. Avaliar o efeito do ângulo de posição da fresa em três níveis sobre a tensão residual induzida pela operação de fresamento do aço ABNT 4340, por meio de análise qualitativa, e quantitativa.

4. Avaliar a influência da velocidade de corte em dois níveis sobre a tensão residual induzida pela operação de fresamento do aço ABNT 4340, por meio de análise qualitativa, e quantitativa.

5. Medir a rugosidade da superfície gerada pela operação de fresamento do aço ABNT 4340 em todas as condições ensaiadas por meio de rugosímetro para garantir que o desvio médio aritmético (Ra) da superfície esteja com no máximo 2,5 $\mu \mathrm{m}$ [2].

$\mathrm{O}$ fresamento é uma operação de usinagem que tem por objetivo gerar superfícies por meio de remoção progressiva de uma quantidade pré-determinada de material da peça. Nesta operação, a ação de corte e alcançada pela rotação da ferramenta (fresa) enquanto a peça permanece fixa em uma mesa que se move realizando o movimento de avanço [3].

A fresa é uma ferramenta que comumente possui várias arestas de corte, podendo variar de uma aresta até mais de cem, o que implica diretamente na taxa de remoção de material, observadas outras condições como potência disponível da máquina, rigidez de fixação da peça, diâmetro da ferramenta, etc.

$\mathrm{Na}$ operação de fresamento frontal destaca-se a de faceamento cuja superfície usinada é gerada pela combinação de arestas de corte localizadas na periferia e na face da fresa.

O aço ABNT 4340 é ligado ao cromo, níquel e molibdênio. É amplamente utilizado na indústria dada a suas ótimas propriedades tais como resistência à fadiga e boa combinação de resistência mecânica e tenaci- 
dade. É amplamente aplicado na fabricação de peças tais, como: virabrequins, bielas, eixos e engrenagens tanto de automóveis quanto aeronaves.

Tratamento térmico é o conjunto de operações de aquecimento a que são submetidos os aços, sob condições controladas de temperatura, tempo, atmosfera e velocidade de resfriamento, com objetivo de alterar as suas propriedades ou conferir-lhes características determinadas [4]. São utilizados para controlar as diversas fases que podem se formar na microestrutura do aço, bem como a morfologia e o tamanho de grão. Os tratamentos térmicos possibilitam a formação de microconstituintes conhecidos como ferrita, bainita, perlita, martensita e austenita. Possibilitam a formação de aços com diferentes fases e morfologias onde a composição entre os diferentes microconstituintes torna-se fator decisivo para as propriedades mecânicas finais do material podendo ser ajustada em conformidade com as exigências de projeto [5].

Dentre os principais tratamentos térmicos destacam-se:

1. recozimento;

2. normalização;

3. esferoidização;

4. tempera.

Recozimento é o tratamento térmico realizado com o fim de alcançar um ou mais dos seguintes objetivos:

1. remover tensões devidas aos tratamentos mecânicos a frio ou a quente;

2. reduzir a dureza para melhorar a usinabilidade;

3. alterar as propriedades mecânicas como limite de escoamento, resistência à tração, alongamento percentual;

4. modificar as características elétricas e magnéticas.

O recozimento total ou pleno consiste no aquecimento do aço acima da zona crítica por tempo suficiente para transformação de toda microestrutura em austenita, seguido de resfriamento lento realizado sob condições que permitam a formação dos constituintes previstos pelo diagrama de equilíbrio ferro carbono. Normalmente desliga-se o forno e permite que a peça se resfrie em seu interior [4]. A microestrutura típica que se obtém com o recozimento pleno do aço ABNT 4340 é composta por ferrita e perlita [6].

A normalização consiste no aquecimento do aço a uma temperatura acima da zona crítica por tempo suficiente para transformação de toda microestrutura em austenita, seguido de resfriamento ao ar. A microestrutura típica que se obtém com a normalização é composta por ferrita, perlita, uma certa quantidade de bainita e em alguns casos austenita retida [6].

COLPAERT [7] destaca que a normalização é o tratamento térmico indicado para obter uma estrutura homogênea e refinada e melhorar a resistência e a tenacidade do aço. Além disto, em muitos casos, para se obter uma resposta uniforme a outros tratamentos térmicos (como tempera, por exemplo) é necessário partir de uma estrutura uniforme obtida através de normalização.

Denominam-se tensões residuais aquelas presentes em um sólido sem que nele estejam agindo quaisquer conjunto de forças externas, inclusive peso próprio. Podem estar presentes nos mais diversos componentes e têm papel importante no desempenho destes em realizar suas funções. As tensões residuais se somam às tensões atuantes (externas) podendo aumentar ou diminuir os esforços resultantes desta interação. Assim, o conhecimento da intensidade e da distribuição destas tensões residuais ao longo da profundidade a partir da superfície é muito importante do ponto de vista de integridade estrutural.

Tensões residuais na superfície e em regiões imediatamente abaixo da superfície de componentes usinados é provavelmente o aspecto mais importante na integridade visto sua direta relação com o desempenho do componente quando ele está sujeito a cargas cíclicas.

Tensões de compressão são geralmente benéficas à vida do componente no que se refere a fadiga, fluência, estabilidade dimensional e corrosão sob tensão, enquanto que tensões de tração são prejudiciais [8].

Estudos têm sido conduzidos sobre tensões residuais induzidas por processo de fabricação que envolvem remoção de material. Dentre eles a usinagem, e em especial o fresamento. Tem sido observado que para uma dada peça de um dado material usinado a natureza da distribuição de tensão residual na região da superfície depende da velocidade de corte, da taxa de avanço, profundidade de corte, geometria da ferramenta e da utilização ou não de fluído de corte. $\mathrm{O}$ valor absoluto da tensão residual próximo à superfície é alto e diminui continuamente com a profundidade abaixo da superfície usinada. A tensão residual é normalmente de tração para profundidades de corte maiores e a seco e menores para profundidades de corte menores e com uso de 
fluído de corte, [8].

As características dos componentes mais impactadas pela presença de tensões residuais, bem como sua intensidade e caráter são:

1. Vida em Fadiga

2. Resistência à Fluência

3. Resistência à Corrosão

4. Instabilidade dimensional

Nos processos de usinagem a deformação plástica e variação volumétrica inerentes ao processo se constituem como principais aspectos relacionados a origem das tensões residuais induzidas nas superfícies geradas pelo processo.

Deformação plástica ocorre durante o processo de formação do cavaco e o contato entre a ferramenta e as partes usinadas.

Gradientes térmicos decorrem de deformação plástica bem como do atrito. Caso reúnam-se condições de pressão e temperaturas elevadas, estas podem ser suficientes para promover transformação de fases na superfície o que implica em variação volumétrica [8].

SU [9] apresenta uma boa visão histórica quanto aos trabalhos desenvolvidos sobre tensões residuais nos processos de usinagem, onde consta que os primeiros estudos foram basicamente experimentais. Um dos pioneiros foi [10], o qual publicou trabalhos fundamentais que ainda hoje são referenciados.

LIU et al. [11] buscaram determinar os efeitos dos parâmetros de usinagem na tensão residual induzida na superfície usinada. Observaram que para corte ortogonal quatro variáveis são determinantes no padrão da tensão residual gerada na superfície usinada, sendo eles:

1. comprimento do plano de cisalhamento;

2. desgaste de flanco;

3. geometria da cunha cortante;

4. profundidade de corte.

Segundo eles, a geometria da cunha cortante determina o padrão de tensão residual próximo à superfície. Menores profundidades de corte, não necessariamente produzem menores tensões sub-superficiais. $\mathrm{O}$ desgaste de flanco aumenta a temperatura de corte. Menores restrições durante o processo de deformação resultam em menores níveis de tensão residual.

XIE et al. [12] investigaram o efeito do desgaste da ferramenta na tensão residual induzida nos processos de usinagem chegando a resultados semelhantes aos apresentados por [11].

SADAT et al. [13] ao realizarem ensaios de corte ortogonal em AISI 4340 buscando verificar os efeitos da velocidade de corte, avanço e profundidade de corte no perfil de tensão residual chegaram à conclusão que o valor absoluto da tensão residual aumentou com o aumento da profundidade abaixo da superfície usinada.

TOTTEN et al [14] traz que a energia de corte utilizada nos processos de usinagem resulta em aumento de temperatura e deformação plástica. Três fatores que podem induzir tensões residuais podem ser destacados.

1. Deformação plástica envolvendo atrito e recalque de material na superfície tende a gerar tensão residual de compressão.

2. Aumento de temperatura que normalmente causa expansão, e que por sua vez é restringida pelo material como um todo. A tensão resultante devido à expansão térmica pode exceder a tensão de escoamento e por sua vez a superfície será perturbada. Durante o próximo resfriamento tensão residual de tração será induzida.

3. Caso a peça seja de material endurecível por tratamento térmico, martensita pode se formar como resultado do rápido aquecimento e resfriamento e induzir tensão residual de compressão.

Nas operações de fresamento em todos os casos a tensão residual induzida é resultado do balanço entre os três fatores mencionados. O processo mecânico é usualmente dividido em formação do cavaco e atrito e recalque de material da superfície fresada. Formação do cavaco (i.e., separação metálica) tende a gerar tensão residual de tração, enquanto atrito e recalque de material da superfície tende a induzir tensão residual de compressão. A maior parte do calor gerado fica no cavaco e é removido da peça. 
O efeito da temperatura é favorável em fresamento concordante, bem como nas operações de faceamento com eixo de corte inclinados e o efeito de atrito e recalque de material em fresamento discordante e operações de faceamento com eixo perpendicular [14].

EL-KHABEERY et al. [8] realizaram um estudo com objetivo de avaliar o efeito da velocidade de corte, profundidade de corte, taxa de avanço e limite de resistência do material ensaiado sobre a tensão residual induzida na superfície obtida por fresamento utilizando uma fresa tangencial. Os materiais ensaiados foram, uma liga de alumínio: AlMnSi, bronze: MS63, e aço: graus 34, 50 e 60. Concluíram que o aumento da velocidade de corte resultou em redução gradual na intensidade da tensão residual independente da taxa de avanço e que para materiais com limite de resistência à tração de até $363 \mathrm{MPa}$ quanto maior esta propriedade menor a intensidade da tensão residual. Enquanto que para materiais com limite de resistência a tração maiores que $363 \mathrm{MPa}$ ocorre aumento rápido da tensão residual. Caracterizando um ponto de inflexão para o comportamento da tensão residual induzida em função do limite de resistência â tração. Este comportamento sugere que a partir de uma determinada resistência à tração passa-se a predominar os efeitos térmicos, entretanto não a ponto de ocorrer formação de martensita, visto que caso isto ocorresse teria-se a predominância de tensões residuais de compressão.

Diversas técnicas para medição de tensões residuais foram desenvolvidas ao longo dos anos, tanto quantitativas quanto qualitativas.

Geralmente estas técnicas são classificadas em dois grupos, destrutivas e não destrutivas. As destrutivas comprometem a utilização do componente após a medição enquanto que a não destrutiva, possibilita a utilização, em alguns casos, do componente ensaiado. Algumas também são consideradas semi-destrutivas, entretanto dependerá do grau de responsabilidade que o componente desempenhará. Neste trabalho a técnica empregada foi a do furo central. Este método consiste na realização de um furo, com diâmetro entre 0,8 e 5 milímetros, na amostra ou peça que se deseja obter as tensões residuais. Mediante a realização deste furo ocorre o relaxamento da amostra nas adjacências ao furo realizado. As deformações devidas a este relaxamento são então medidas por extensômetros e a partir destas aplica-se os conceitos da teoria da elasticidade para se calcular as tensões residuais presentes. A técnica é dita incremental tendo em vista que este furo é realizado de forma incremental ao longo da profundidade e as deformações mediadas para cada incremento.

O método foi inicialmente proposto em de 1934 por Mathar, ASTM [15].

Desde então vários trabalhos foram realizados com uso da técnica vindo a ser normatizada pela ASTM 837 em 1983.

Informações mais detalhadas sobre os diversos métodos para medições de tensões residuais podem ser consultadas em [15, 16 e 17].

Nos processos de usinagem uma série de fatores exercem influência sobre a tensão residual induzida na superfície gerada. Estudos específicos relacionados aos fatores aqui estudados da maneira como foram agrupados não são comuns. De um modo geral encontra-se estudos direcionados ao processo de torneamento, [13 e 18], fresamento, [19, 20, 21, 22], furação, [23], entre outros. Uma boa fonte de literaturas relacionadas ao tema pode ser encontrada em trabalhos que buscam predizer o comportamento da tensão residual para os diversos processos de usinagem. Dentre estes pode-se destacar, [24]. Outras fontes são os trabalhos que buscam estudar o comportamento em fadiga em função da tensão residual induzida na superfície, [19, 25 e 26].

\section{MATERIAIS E MÉTODOS}

Os experimentos foram realizados conforme fluxograma apresentado na Figura 1 no Laboratório de Usinagem e Automação do Departamento de Engenharia Mecânica da Universidade Federal de Minas Gerais. 


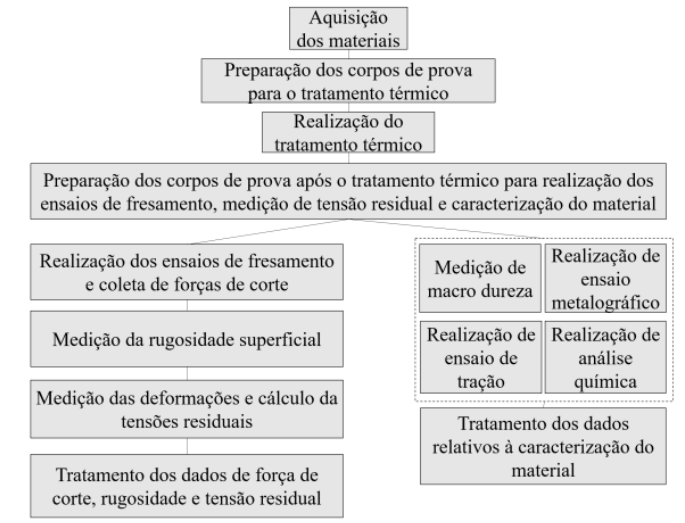

Figura 1: Fluxograma do procedimento experimental.

Os corpos de prova foram adquiridos nas dimensões de 75x60x27 mm, retirados de um único bloco de seção transversal de $254 \times 480 \mathrm{~mm}$. Foi tomado o cuidado para que todos tivessem a dimensão de $75 \mathrm{~mm}$ com mesma orientação, sendo o sentido de laminação. Este cuidado é importante devido à anisotropia do material. Para realização do ensaio de tração foram adquiridas barras nas dimensões de $110 \times 25 \times 25 \mathrm{~mm}$ a partir do mesmo bloco que os demais com a dimensão de $110 \mathrm{~mm}$ com orientação no sentido de laminação. Todos foram obtidos por meio de corte com uso de serra alternativa. Ao todo foram adquiridos trinta e nove blocos para os ensaios de fresamento e seis barras para os ensaios de tração. Na sequência os corpos de prova foram tratados termicamente pelos processos de recozimento e normalização, nas quantidades de 19 e 20 respectivamente.

Após realização do tratamento térmico os corpos de prova foram usinados, com forma e dimensões da Figura 2, em um centro de usinagem Romi modelo Discovery 560 com potência de $9,0 \mathrm{~kW}$ e rotação máxima de 7500 rpm, com comando numérico Siemens 810D.
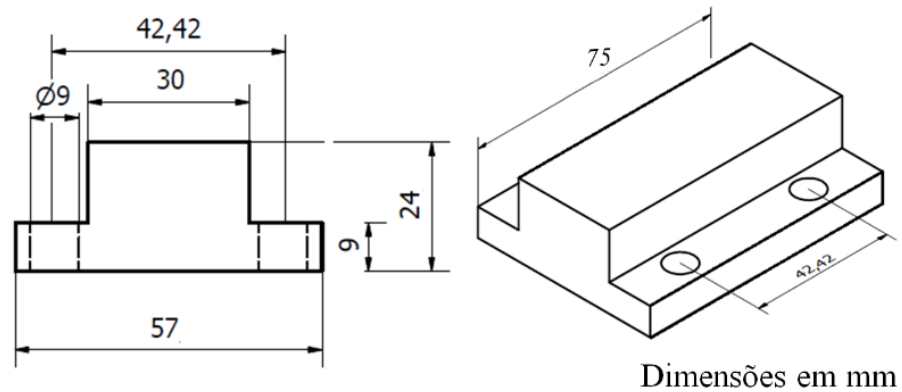

Figura 2: Geometria e dimensões do corpo de prova para o fresamento.

Para caracterização do aço ABNT 4340 tendo como objetivo atestar a conformidade do material adquirido quanto às propriedades mecânicas, composição química e microestrura típicas, foram preparados corpos de prova para ensaio de tração e retiradas amostras para análise química e metalograficas. Um croqui com as principais dimensões dos copos de prova de ensaio de tração com base em [27] é apresentado na Figura 3 , bem como para análise química e metalográfica. 


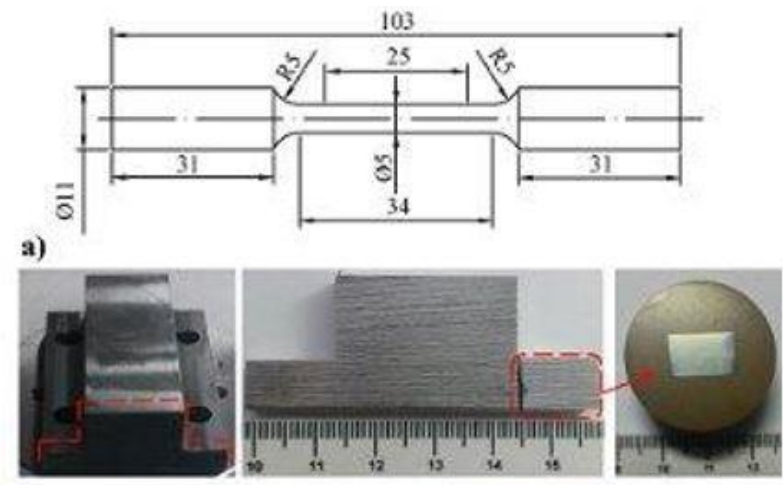

b)

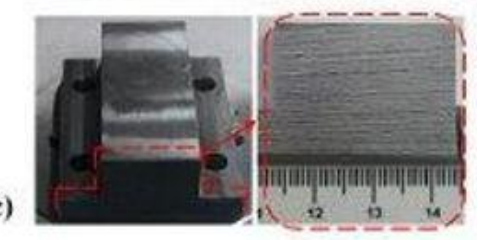

Figura 3: Corpos de prova - a) ensaio de tração; b) ensaio metalográfico; c) análise química.

Realizou-se medição de dureza rockwell na Pontifícia Universidade Católica de Minas Gerais, campus Coração Eucarístico, por meio de um durômetro VEB Wpm modelo 300/216. Foram realizadas 3 medições em cada corpo de prova e realizada a média entre eles. Obteve-se como dureza média $23 \pm 2,40$ e $37 \pm 1,24$ HRC para o material recozido e normalizado respectivamente.

Os ensaios foram realizados segundo um planejamento fatorial $2 \times 3 \times 2$ e com três réplicas.

Uma sequência aleatória foi gerada para realização dos ensaios de fresamento. A profundidade de corte foi mantida constante em $1 \mathrm{~mm}$. Adotou-se espessura do cavaco constante, o que resultou em três avanços distintos para cada ângulo de posição. Para identificação das condições e simplificação do registro dos diferentes dados obtidos com os ensaios bem como se referenciar a eles no texto elaborou-se uma codificação que representa as condições dos fatores que foram variados. Esta codificação está descrita na Figura 4.

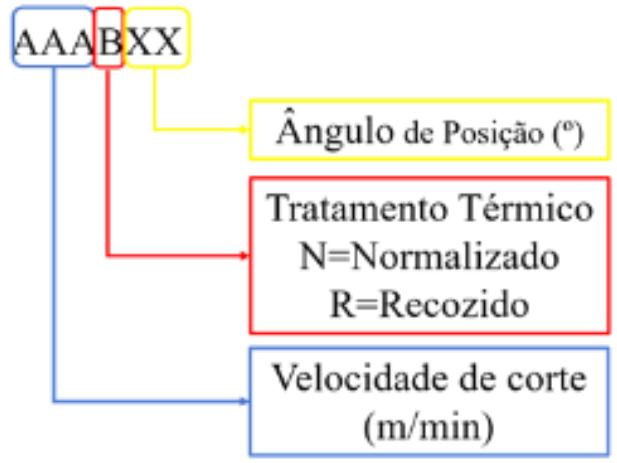

\section{Exemplos:}

\section{$100 \mathrm{~N} 12$}

Velocidade de corte $=100 \mathrm{~m} / \mathrm{min}$

Tratamento Térmico $=$ Normalização

Ângulo de posição $=12^{\circ}$

\section{R45}

Velocidade de corte $=275 \mathrm{~m} / \mathrm{min}$

Tratamento térmico $=$ Recozimento

Ângulo de posição $-45^{\circ}$

Figura 4: Codificação para condições de ensaio.

Quando no texto surgir a necessidade de ser referir a uma condição onde um fator é variado e os outros dois são mantidos constantes aparecerá a letra na respectiva posição referente ao fator no código.

Os corpos de prova foram devidamente numerados. Os ensaios foram realizados segundo uma sequência aleatória.

Os valores para velocidade de corte e avanço foram selecionados baseando-se em recomendação do fabricante por meio de consulta aos respectivos catálogos de ferramentas.

Foram utilizadas três fresas com ângulos de posição distintos, sendo 12,45 e $90^{\circ}$. As fresas, bem como os insertos utilizados são apresentados na Figura 5. Fresas e insertos do fabricante MITSUBISHI CARBI$D E$. 


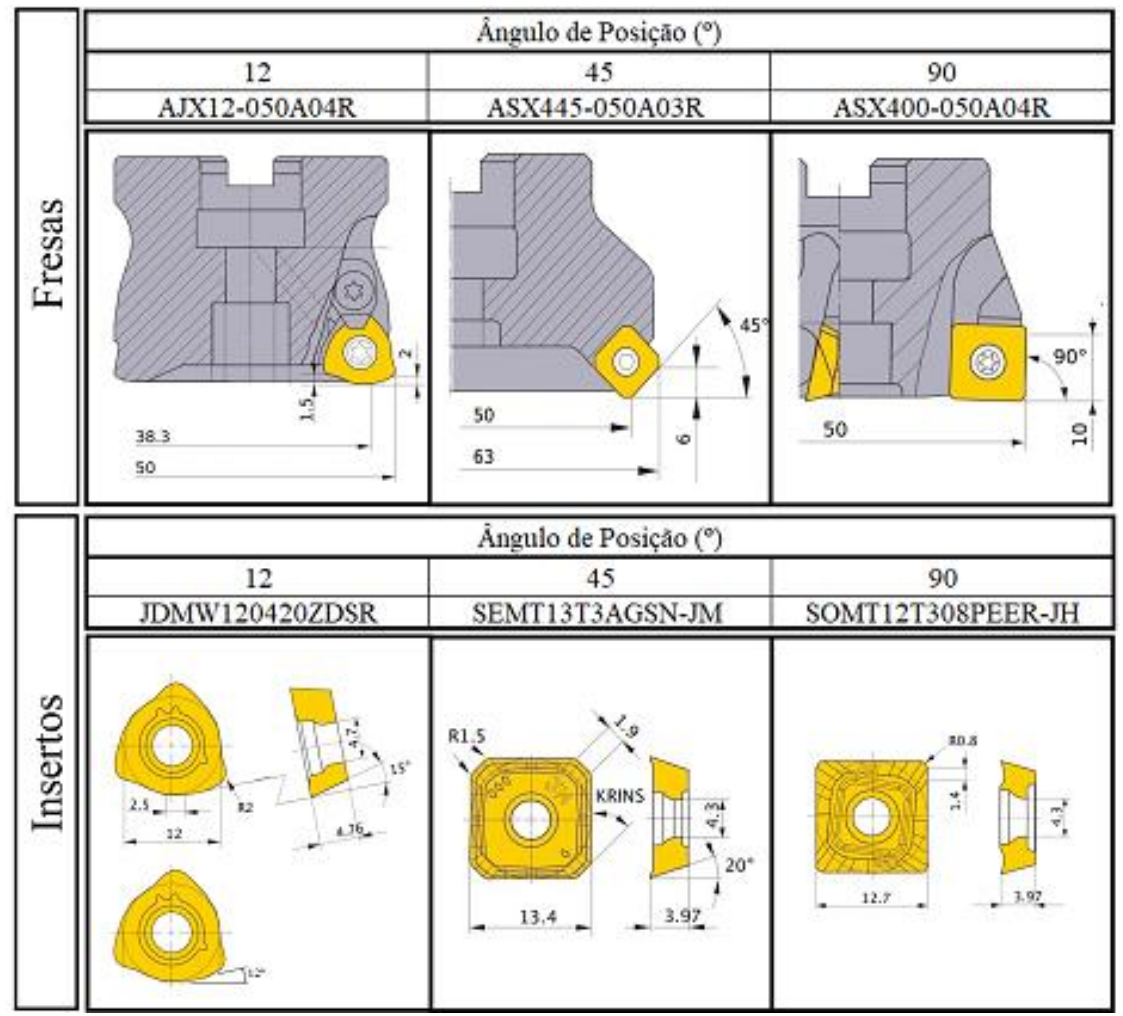

Figura 5: Fresas e insertos utilizados nos ensaios de fresamento

A fresas possuem diâmetro nominal de $50 \mathrm{~mm}$. A largura fresada foi de $30 \mathrm{~mm}$ com o fresamento sendo realizado de forma tal que a linha de centro da fresa fosse coincidente com a linha de simetria da peça na direção da dimensão de 75mm. Os parâmetros de corte estão resumidos na Tabela 1.

\begin{tabular}{|c|c|c|c|c|c|c|c|}
\hline & \multicolumn{6}{|c|}{ Ângulo de posição ( $\left(^{\circ}\right)$} \\
\hline & & \multicolumn{2}{|c|}{12} & \multicolumn{2}{|c|}{45} & \multicolumn{2}{|c|}{90} \\
\hline $\begin{array}{c}\mathrm{Vc} \\
(\mathrm{m} / \mathrm{min})\end{array}$ & $\begin{array}{c}\text { Rotação } \\
\text { (RPM) }\end{array}$ & $\begin{array}{c}\mathbf{f z} \\
(\mathrm{mm} / \mathrm{rev})\end{array}$ & $\begin{array}{c}\mathrm{Vf} \\
(\mathrm{mm} / \mathrm{min})\end{array}$ & $\begin{array}{c}\mathbf{f z} \\
(\mathrm{mm} / \mathrm{rev})\end{array}$ & $\begin{array}{c}\mathrm{Vf} \\
\mathrm{mm} / \mathrm{min}\end{array}$ & $\begin{array}{c}\mathbf{f z} \\
(\mathrm{mm} / \mathrm{rev})\end{array}$ & $\begin{array}{c}\mathrm{Vf} \\
\mathrm{mm} / \mathrm{min}\end{array}$ \\
\hline 100 & 637 & \multirow{2}{*}{0,38} & 242 & \multirow{2}{*}{0,21} & 134 & \multirow{2}{*}{0,15} & 96 \\
\hline 275 & 1765 & & 671 & & 371 & & 265 \\
\hline
\end{tabular}

Tabela 1: Parâmetros de corte para o ensaio de fresamento.

Os sinais de força foram adquiridos durante a operação de fresamento por meio de um dinamômetro Kistler modelo 9272. Utilizou-se uma placa de aquisição de dados National Instruments USB - 6366 fabricada pela National Instruments, conectada a um computador equipado com Windows XP Professional, processador Intel i5-2500 e memória RAM de 4 gigabytes. O software utilizado para aquisição do sinal de força foi o NI LabView SignalExpress 2013. Os dados coletados foram exportados para o Microsoft Excel 2007 para posterior análise. A Figura 6 representa a forma como foi realizada a montagem. 


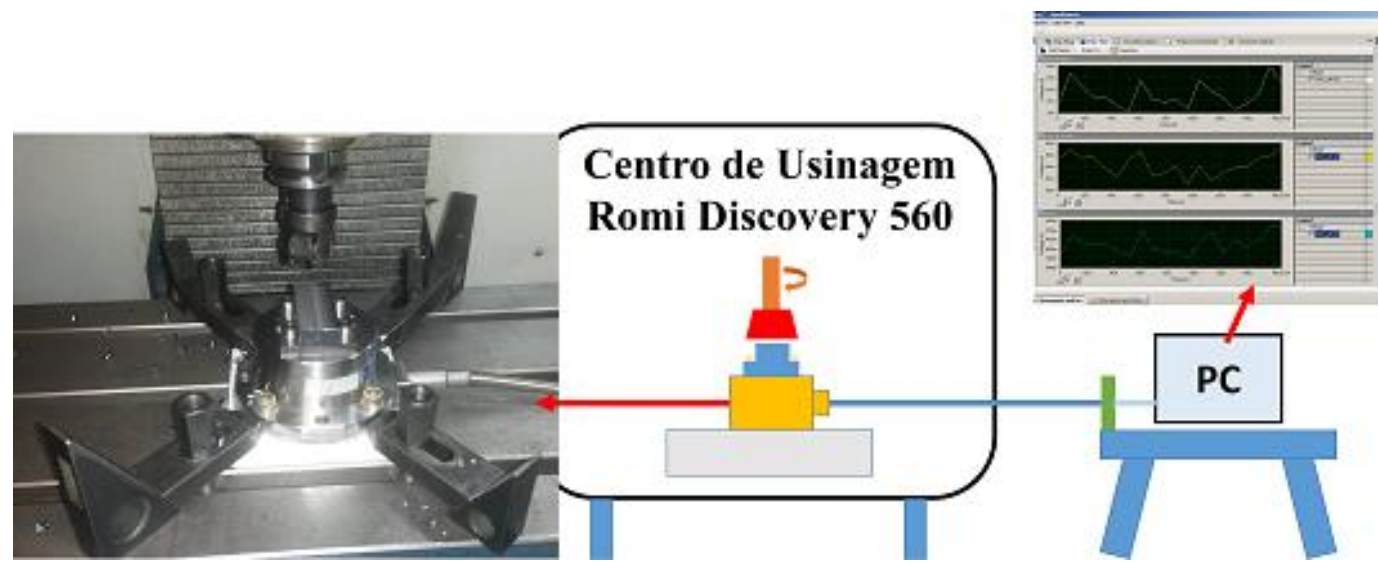

Figura 6: Esquema de montagem para realizar ensaio de fresamento com aquisição de forças.

Com o objetivo de minimizar possíveis efeitos decorrentes de desgaste das ferramentas de corte, cada ensaio foi realizado com uma aresta nova da ferramenta. Mesmo as fresas tendo alojamentos para vários insertos, os ensaios foram realizados usando-se apenas um, com objetivo de simplificar as análises.

A determinação das tensões residuais foi realizada por meio do método do furo central. Apesar de ser um método consolidado que vem sendo aplicado desde os anos de 1930, para que se obtenha medições precisas e confiáveis é preciso observar uma série de fatores que, se não observados, podem contribuir negativamente para o resultado. Um conjunto de boas práticas foi observado em [28]. Com objetivo de se reduzir erros associados ao processo de medição tais como alinhamento, movimento do corpo de prova durante a medição, vibração, bem como outros, foi desenvolvido e fabricado um dispositivo para receber o equipamento RS-200 Milling Guide, fabricado pela Vishay Precision Group, acomodar e fixar o corpo de prova após o seu correto posicionamento. Tal dispositivo é apresentado na Figura 7.

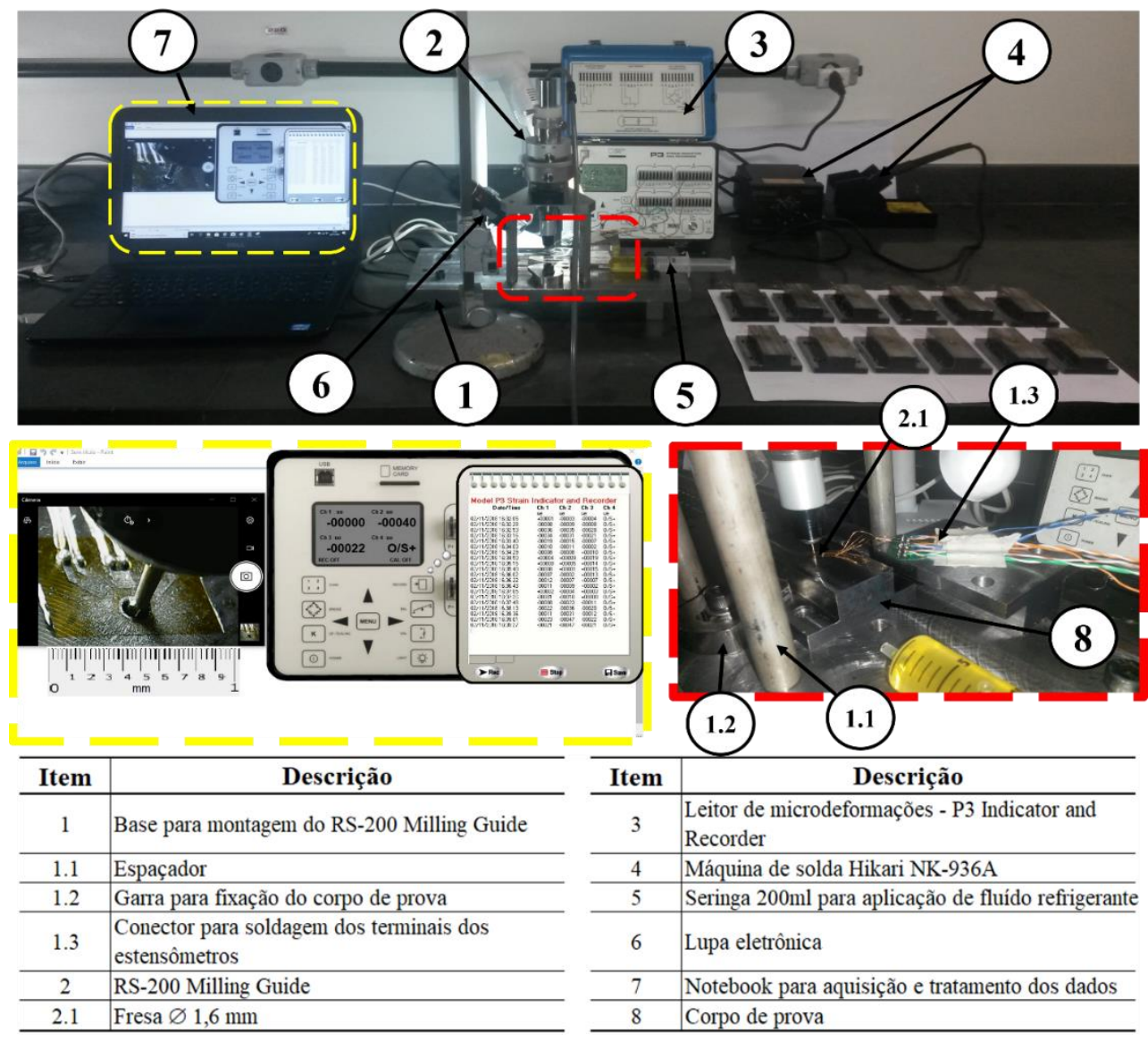

Figura 7: Montagem para medição de microdeformações. 
A roseta de extensômetros foi afixada ao corpo de prova por meio do adesivo Permobond 793. Para isto primeiramente foi realizada limpeza da superfície com acetona e ataque com solução de nítal 10\%. A posição onde a roseta foi instalada no corpo de prova pode ser observada na Figura 8. O extensômetro número 1 foi posicionado no sentido longitudinal (cota de $75 \mathrm{~mm}$ ) enquanto que o de número 3 no sentido transversal (cota de 30mm).
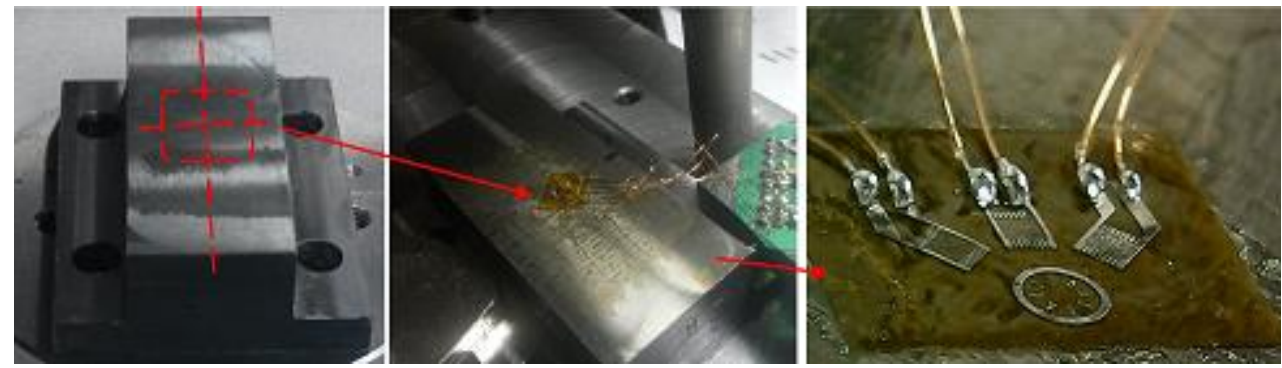

Figura 8: Posição de instalação da roseta para medição das deformações aliviadas.

\section{RESULTADOS}

Os resultados referentes à caracterização do aço ABNT 4340, limite de resistência à tração, alongamento percentual, composição química e microestruturas são compatíveis com valores de referência para este material nas condições ensaiadas.

\subsection{Força de usinagem}

A força de usinagem foi obtida por meio da aplicação da equação 1 [1] com os dados obtidos por meio do dinamômetro.

$$
F_{u}=\sqrt{F_{a p}^{2}+F_{f}^{2}+F_{p}^{2}}
$$

Onde:

$\mathrm{F}_{\mathrm{ap}}=$ força de apoio

$\mathrm{F}_{\mathrm{f}}=$ força de avanço

$\mathrm{F}_{\mathrm{p}}=$ força passiva

O efeito de cada fator sobre a força de usinagem é apresentado nas figuras 9, 10 e 11.

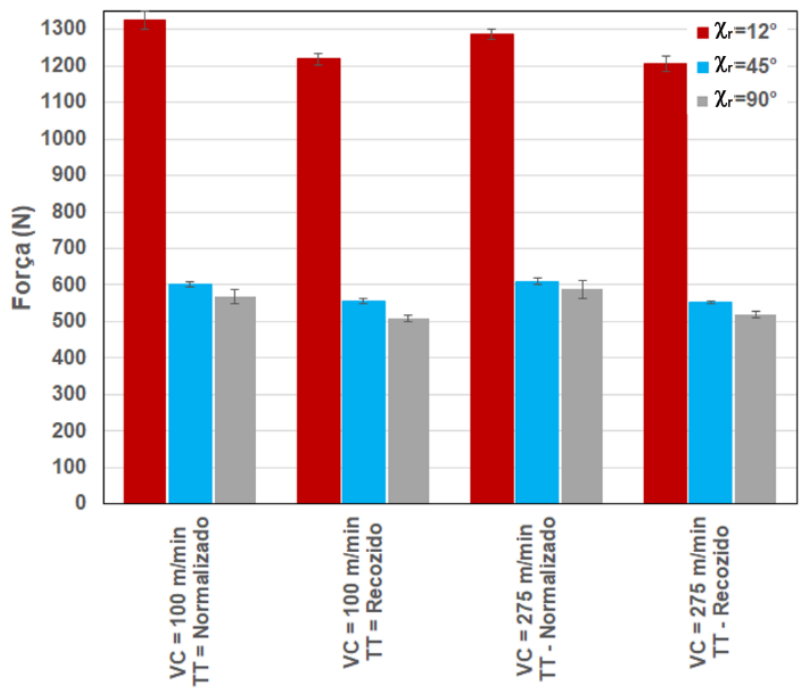

Figura 9: Comportamento da força de usinagem $(\mathrm{Fu})$ em função do ângulo de posição. 


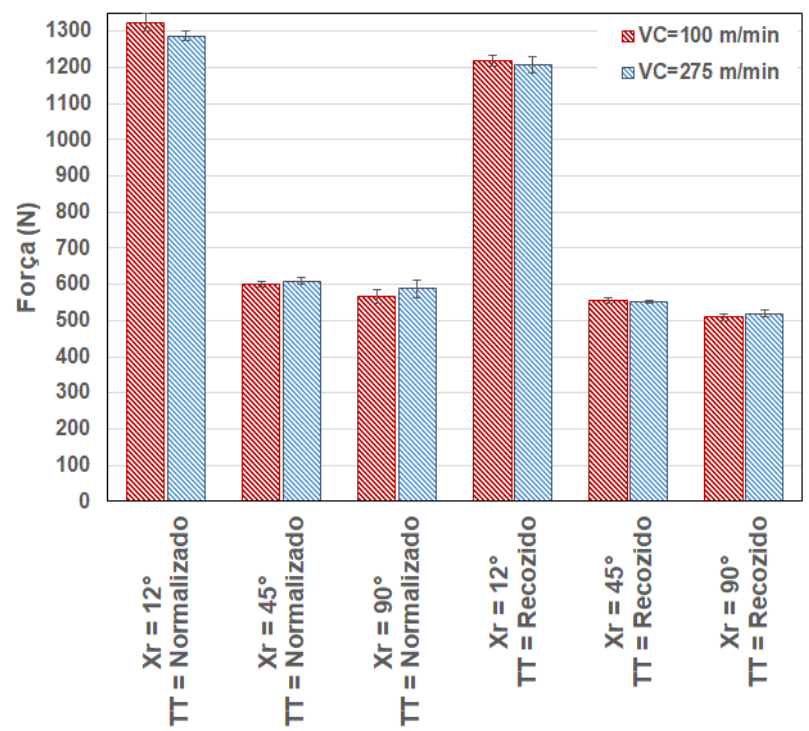

Figura 10: Comportamento da força de usinagem (Fu) em função da velocidade de corte.

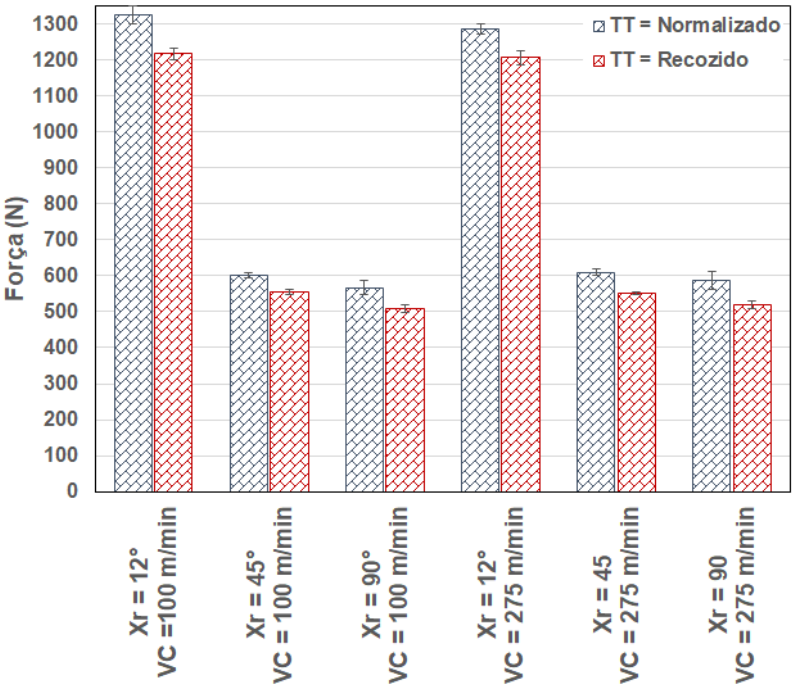

Figura 11: Comportamento da força de usinagem (Fu) em função do tratamento térmico.

Para se obter uma análise quantitativa quanto ao comportamento da força de usinagem e suas componentes, foi realizada uma análise de variância, ANOVA.

Foram utilizados os dados referentes às três réplicas realizadas considerando os três fatores variando em seus respectivos níveis. A Figura 12 c demonstra o resultado do teste de Anderson-Darling para verificar se os dados podem ser aproximados por uma distribuição normal. 

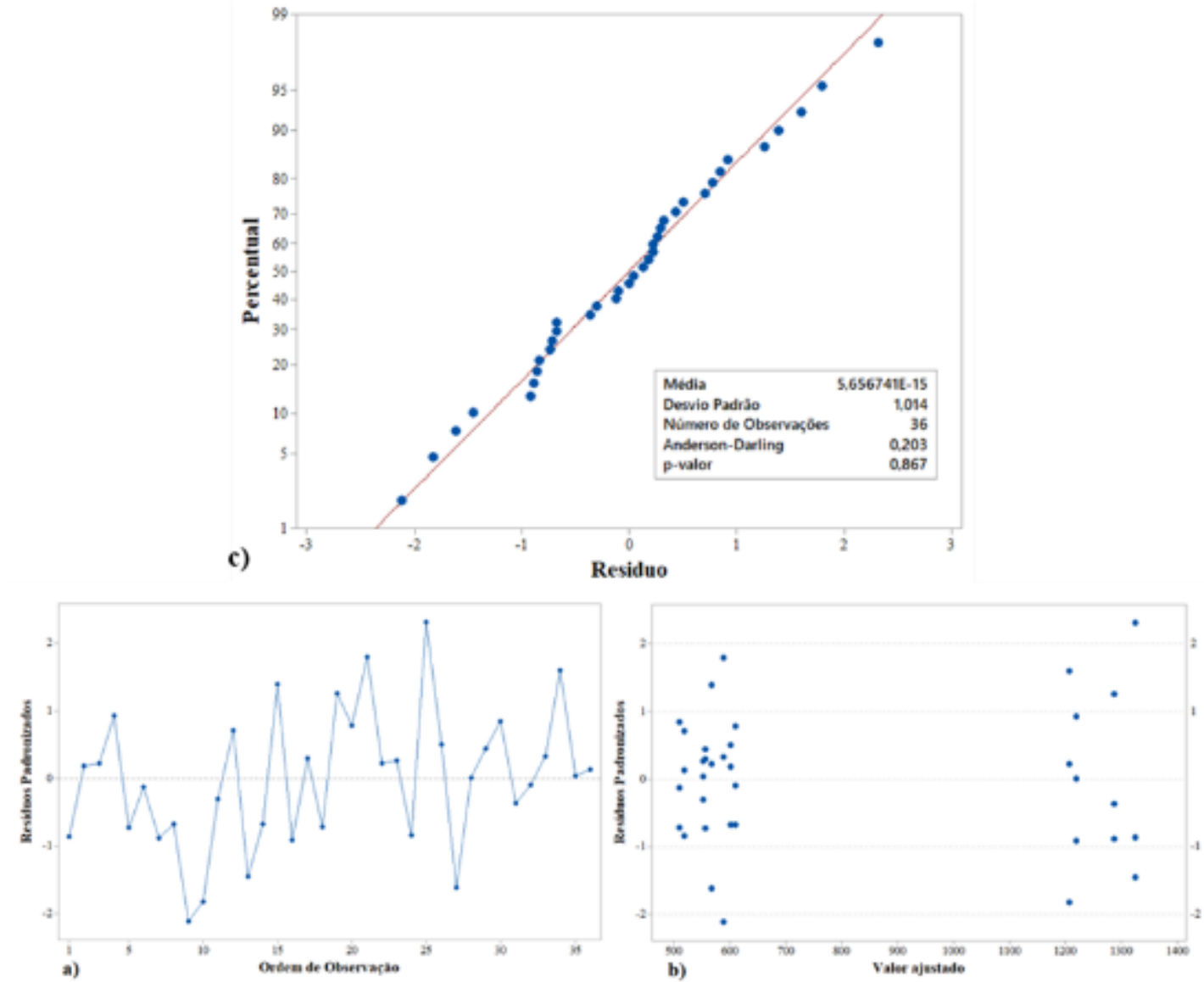

Figura 12: c) Teste de probabilidade normal para a força de usinagem; a) análise dos resíduos $x$ ordem; b) análise dos resíduos $\mathrm{x}$ ajustes.

Como o p-valor é maior que 0,05 , superior ao nível de significância de 0,05 para um teste de confiança de $95 \%$, tem-se a confirmação de que a distribuição de probabilidade pode ser aproximada pela distribuição normal. Para validação do modelo realizou-se análise dos resíduos padronizados para os dados. Na Figura 12 a e b, podem ser observados os gráficos de resíduos versus ordem e resíduos versus ajuste. É possível perceber que os resíduos estão distribuídos aleatoriamente ao longo do tempo. Montgomery e Runger (2016), apud PEREIRA (2017) [29] relacionam-se à necessidade de a média ser zero e variância constante. Afirmam que os erros seguem a distribuição normal com média zero e variância constante, quando cerca de $68 \%$ dos resíduos padronizados estejam entre os limites \pm 1 e $95 \%$ entre os limites \pm 2 . De acordo com a Figura 12 b) dos 36 pontos, 27 estão compreendidos no intervalo entre -1 e 1, 75\%, 34 entre -2 e 2, 94,4\%, o que não chega a comprometer a condição de distribuição normal com média zero e variância constante.

A Tabela 2 resume os dados da ANOVA para a força de usinagem $\mathrm{F}_{\mathrm{u}}$. A análise retornou um valor de R2 de 99,86\%. Isto indica que o modelo é adequado para avaliar o comportamento em estudo. Ainda observando a Tabela 2 nota-se que entre os efeitos principais o tratamento térmico e o ângulo de posição se mostraram significativos ao nível de confiança adotado tanto isoladamente quanto às interações de segunda ordem. Quanto às interações de terceira ordem nenhum efeito principal se mostrou significativo. 


\begin{tabular}{|c|c|c|c|c|c|}
\hline Fonte & GL & SQ (Aj.) & $\mathrm{QM}(\mathrm{Aj})$ & Valor F & p-valor \\
\hline Modelo & 11 & 3941191 & 358290 & 1588.94 & 0,000 \\
\hline Linear & 4 & 3935183 & 983796 & 4362.92 & 0,000 \\
\hline Ve & 1 & 60 & 60 & 0,27 & 0.610 \\
\hline TT & 1 & 43182 & 43182 & 191.50 & 0.000 \\
\hline $\mathrm{Xr}$ & 2 & 3891941 & 1945970 & 8629.96 & 0.000 \\
\hline Interaçōes de 2 fatores & 5 & 5313 & 1063 & 4.71 & 0,004 \\
\hline Vcx TT & 1 & 0 & 0 & 0.00 & 0,993 \\
\hline $\mathrm{Vex} \mathrm{Xr}_{\mathrm{r}}$ & 2 & 2549 & 1274 & 5.65 & 0,010 \\
\hline TT $\times X_{r}$ & 2 & 2764 & 1382 & 6,13 & 0.007 \\
\hline Interaçôes de 3 fatores & 2 & 695 & 347 & 1.54 & 0.235 \\
\hline $\mathrm{Vc} \times \mathrm{TT} \times \mathrm{Xr}$ & 2 & 695 & 347 & 1,54 & 0,235 \\
\hline Erro & 24 & 5412 & 225 & & \\
\hline Total & 35 & 3946602 & & & \\
\hline \multirow{2}{*}{ Sumário Modelo } & $\mathrm{S}$ & $\mathrm{R} 2$ & R2 (Aj.) & R2 (pred) & \\
\hline & 15.016 & $99,86 \%$ & $99.80 \%$ & $99.69 \%$ & \\
\hline
\end{tabular}

Tabela 2: Análise de variância para a força de usinagem.

Na Figura 13 pode ser observado os efeitos principais para os três fatores utilizados no experimento.

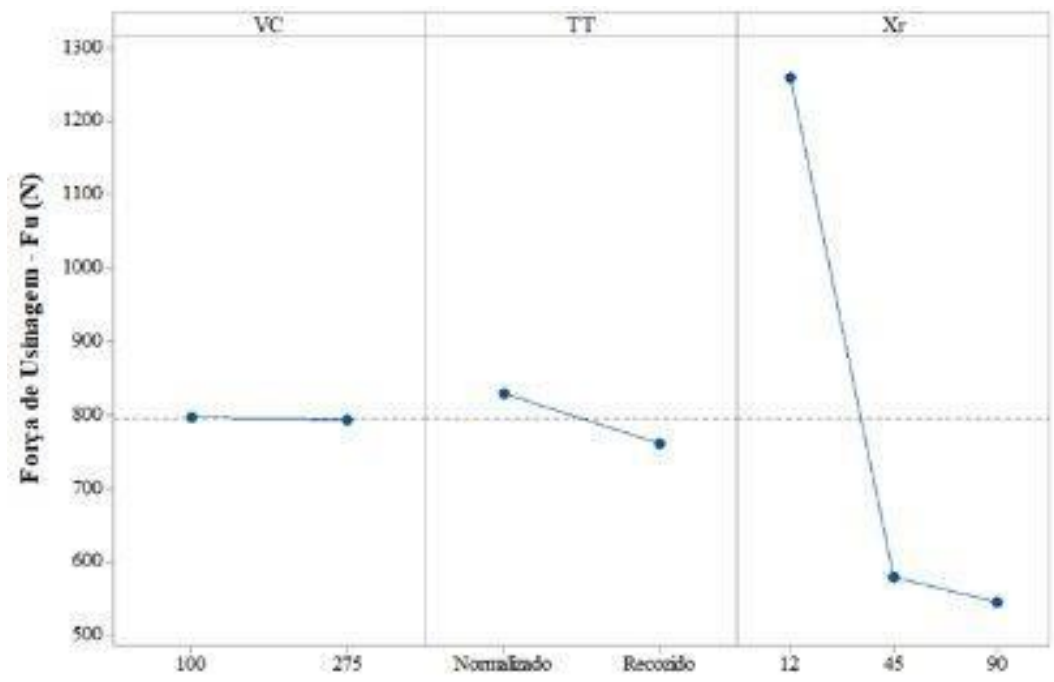

Figura 13: Efeito principal para velocidade de corte, tratamento térmico e ângulo de posição sobre a força de usinagem.

Percebe-se que dos três fatores apenas a velocidade de corte não exerce influência sobre força de usinagem. $\mathrm{O}$ ângulo de posição quando variado para $12^{\circ}$ de forma mais pronunciada. Na Figura 14 podem ser observados os efeitos das interações entre os três fatores considerados. Graficamente fica evidente que somente as interações de segunda ordem entre a velocidade de corte e o ângulo de posição e entre o tratamento térmico e o ângulo de posição são significativos ao nível de confiança considerado. 


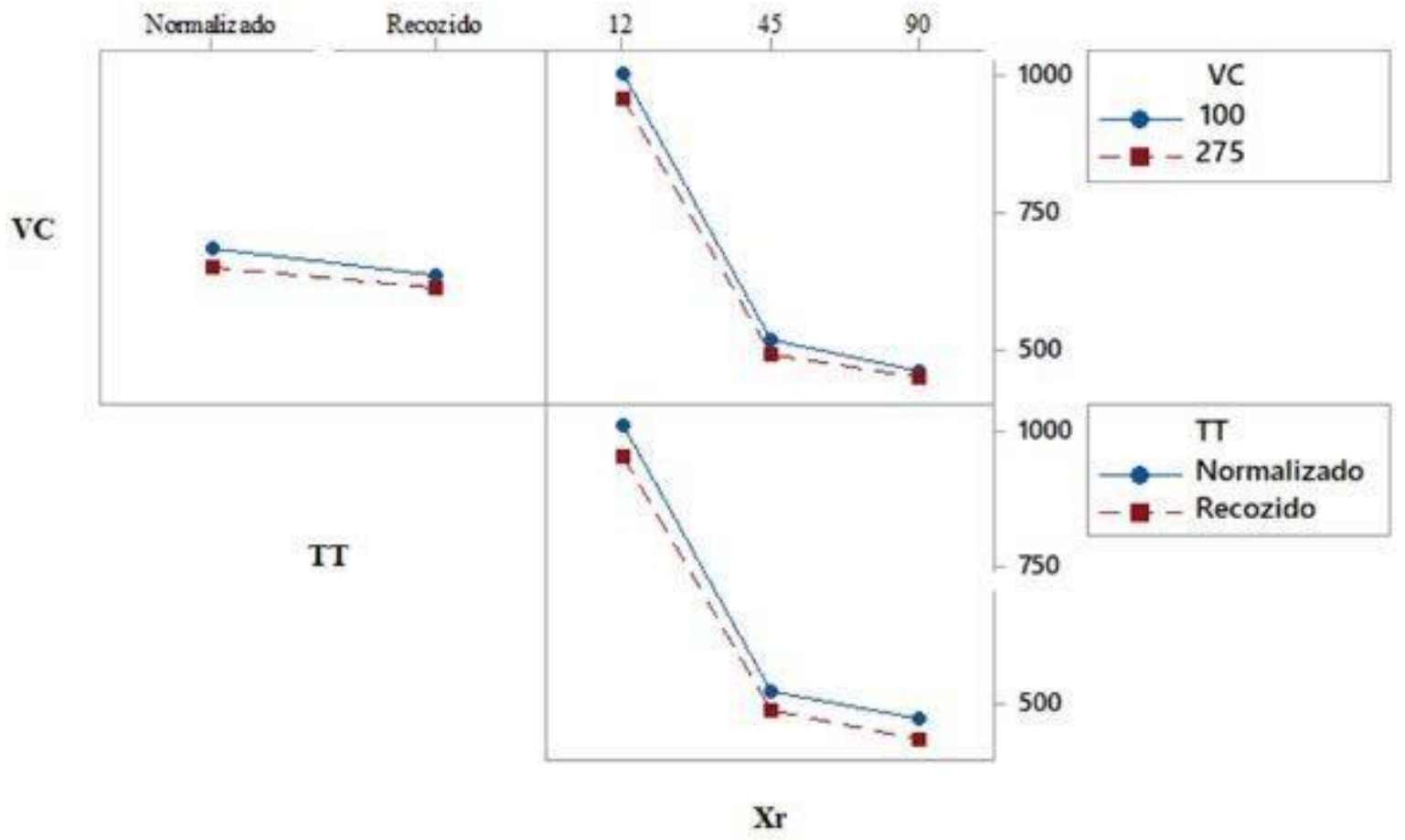

Figura 14: Efeito das interações entre a velocidade de corte, o tratamento térmico e o ângulo de posição sobre a força de usinagem

Nenhuma interação de terceira ordem se mostrou significativa ao nível de confiança considerado.

Em resumo tem-se que:

1. o aumento do ângulo de posição implica na redução da força de usinagem $\left(\mathrm{F}_{\mathrm{u}}\right)$ e suas componentes, à exceção da componente passiva $\left(\mathrm{F}_{\mathrm{p}}\right)$ que quando se varia de 45 para $90^{\circ}$ ocorre aumento;

2. o aumento da velocidade de corte não implica em variação significativa na força de usinagem $\left(\mathrm{F}_{\mathrm{u}}\right)$. Entretanto, implica em aumento das componentes paralela à direção de avanço $\left(/ / \mathrm{V}_{\mathrm{f}}\right) \mathrm{e}$ passiva $\left(\mathrm{F}_{\mathrm{p}}\right)$;

3. a condição do material quanto ao tratamento térmico em normalizado implica em aumento da força de usinagem $\left(\mathrm{F}_{\mathrm{u}}\right)$ e suas componentes;

\subsection{Tensões residuais}

Os dados referentes às deformações coletados foram tratados no software $H$-drill, que é fornecido juntamente com o equipamento RS-200 Milling Guide. Como saída o software fornece uma tabela de dados e três gráficos. A tabela apresenta os dados referentes às deformações medidas, propriedades como tensão de escoamento e modulo de elasticidade do material utilizadas para cálculo, características dos extensômetros da roseta, erro padrão, as tensões residuais em duas direções, para o caso do presente trabalho estas direções correspondem à paralela e perpendicular à direção de avanço, tensões principais máxima e mínima bem como o ângulo entre a tensão principal e o extensômetro número 1, posicionado paralelo à direção de avanço, e respectivas tensões cisalhantes.

Um gráfico apresenta as deformações medidas ao longo da profundidade e os outros dois as tensões residuais principal máxima e mínima e nas direções paralela e perpendicular à direção de avanço. Pode-se observar no Gráfico 1 que o perfil das tensões residuais, principal máxima, mínima, paralela e perpendicular à direção de avanço apresentam certa similaridade. 


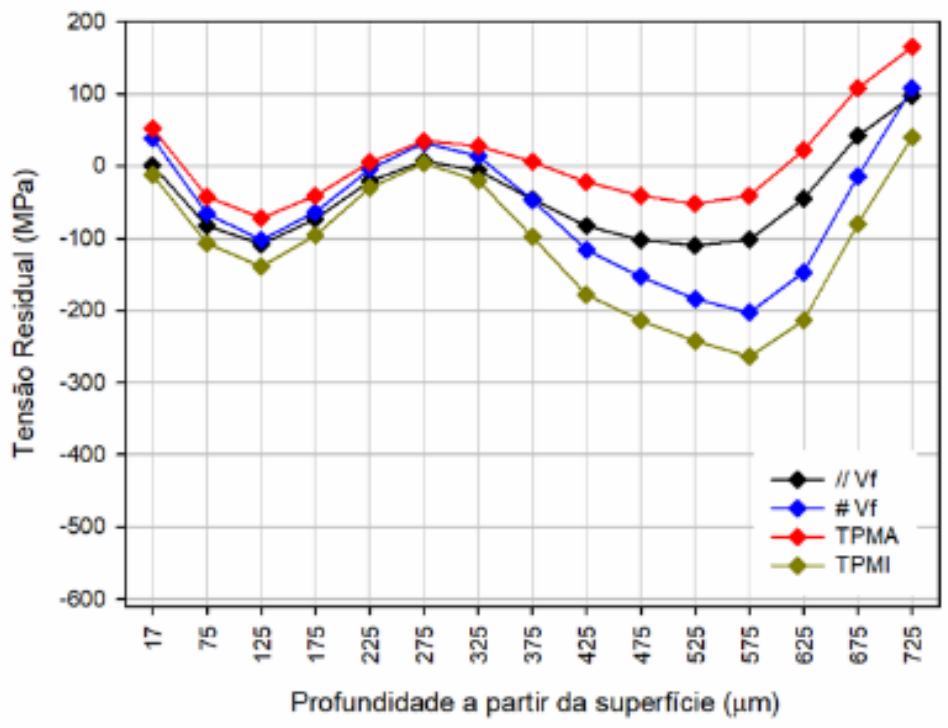

Gráfico 1: Perfil de tensões residuais ao longo da profundidade a partir da superfície para a réplica número 2 na condição 100R45.

Pode-se ainda inferir pela observação do Gráfico 5.1 que as tensões, principal máxima (TPMA) e perpendicular à direção de avanço $\left(\# \mathrm{~V}_{\mathrm{f}}\right)$ possuem intensidades e tendências semelhantes. $\mathrm{O}$ mesmo ocorre para as tensões principal mínima (TPMI) e paralela à direção de avanço $\left(/ / \mathrm{V}_{\mathrm{f}}\right)$. Diante desta constatação e que dentre as três componentes da força de usinagem a de maior intensidade é a perpendicular à direção de avanço, conforme exposto na seção destinada à apresentação dos resultados referentes ao efeito da variação dos três fatores sobre as forças de usinagem e suas componentes e por se tratar de um trabalho comparativo, a análise será conduzida tomando como referência as tensões residuais perpendiculares à direção de avanço $\left(\# \mathrm{~V}_{\mathrm{f}}\right)$. Corrobora esta opção os resultados apresentados por [30] que demonstram respostas similares entre as tensões residuais paralelas e perpendiculares à direção de avanço à variação dos fatores estudados por ele e que, à exceção do tratamento térmico, contém os aqui estudados. Pela observação das Figuras 15 e 16 percebe-se, do ponto de vista qualitativo, grande distinção entre os perfis de tensão residual de cada réplica para uma mesma condição, tratamento térmico, ângulo de posição e velocidade de corte. 


\section{Normalizado}
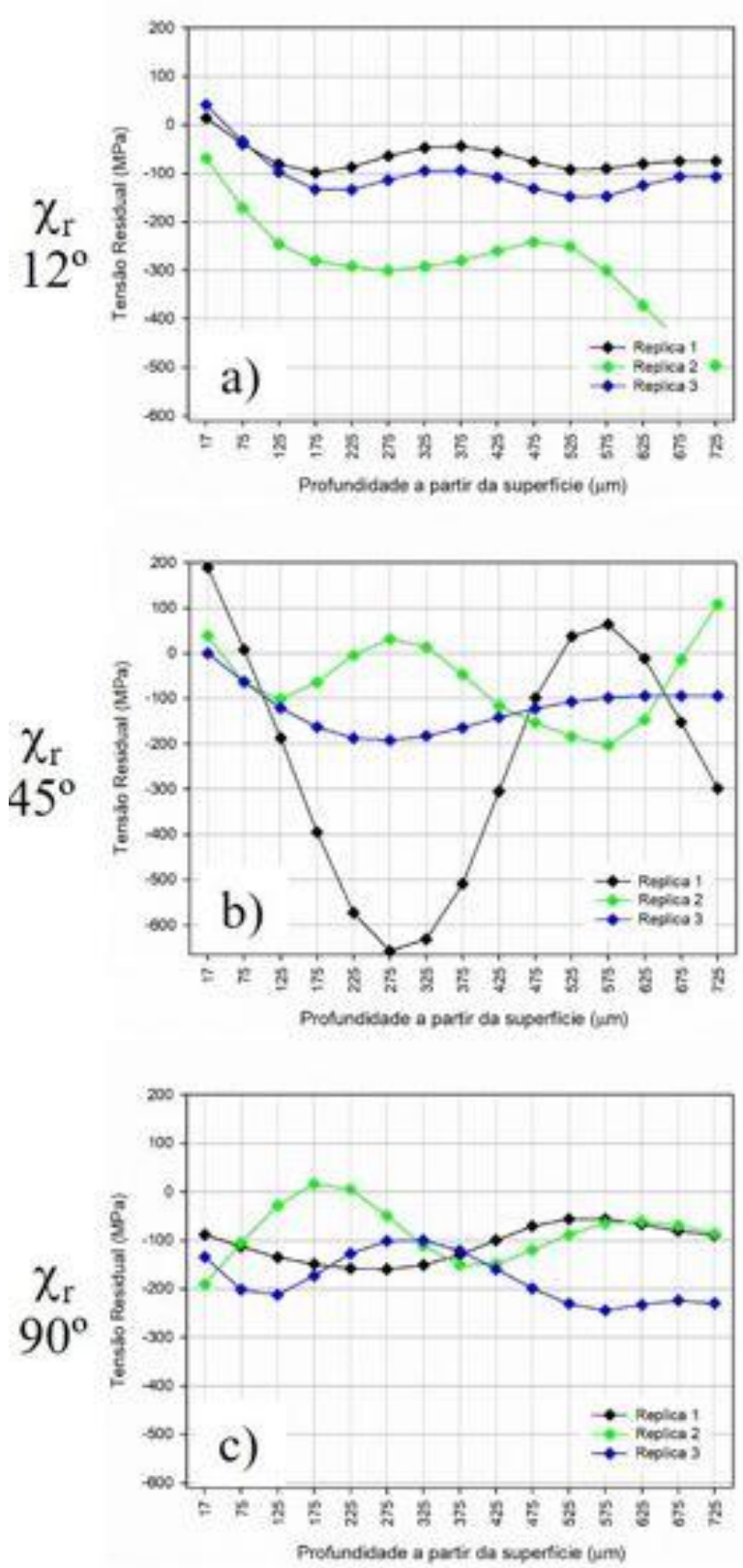

Recozido
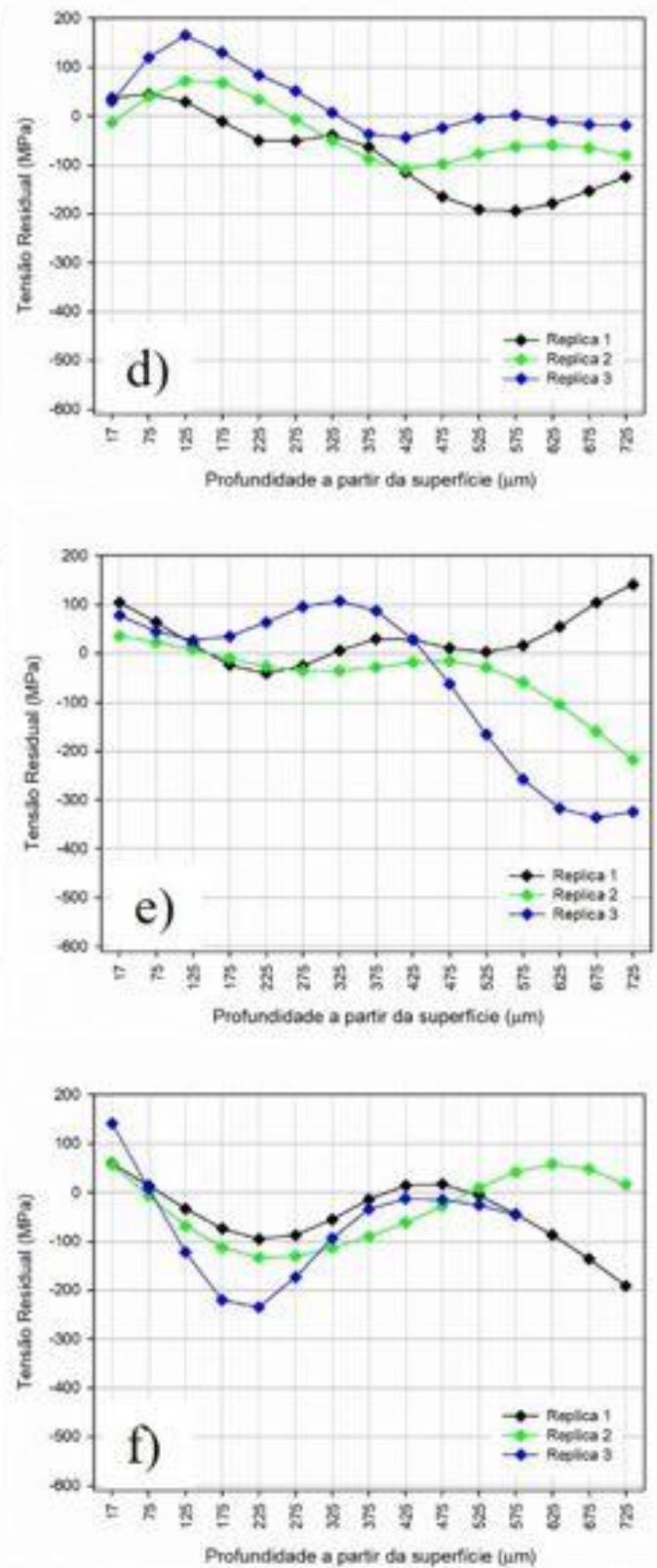

Figura 15: Perfil das tensões residuais perpendiculares à direção de avanço para $V c=100 \mathrm{~m} / \mathrm{min}$ agrupadas pelo tratamento térmico e ângulo de posição da fresa para cada réplica realizada. 


\section{Normalizado}
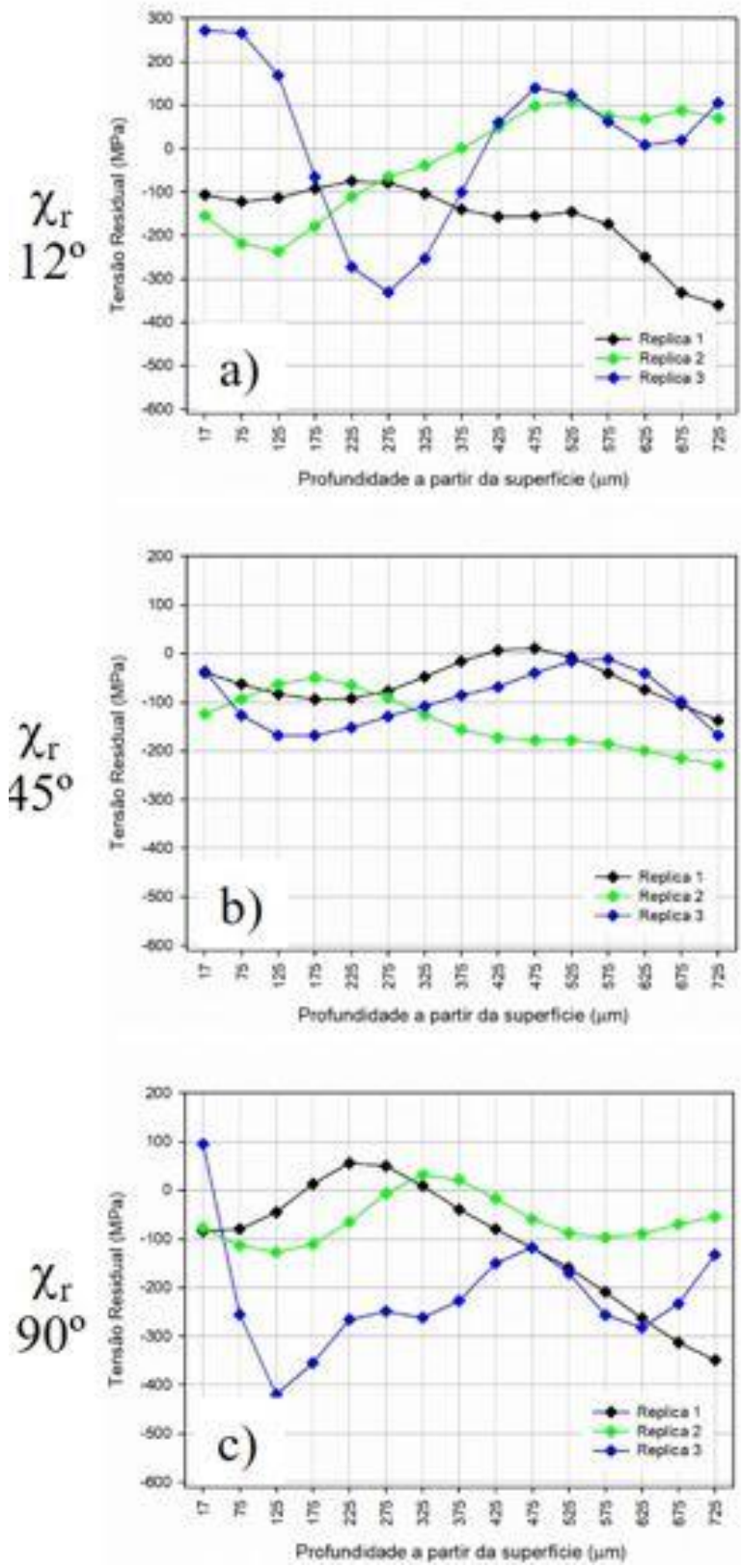

Recozido
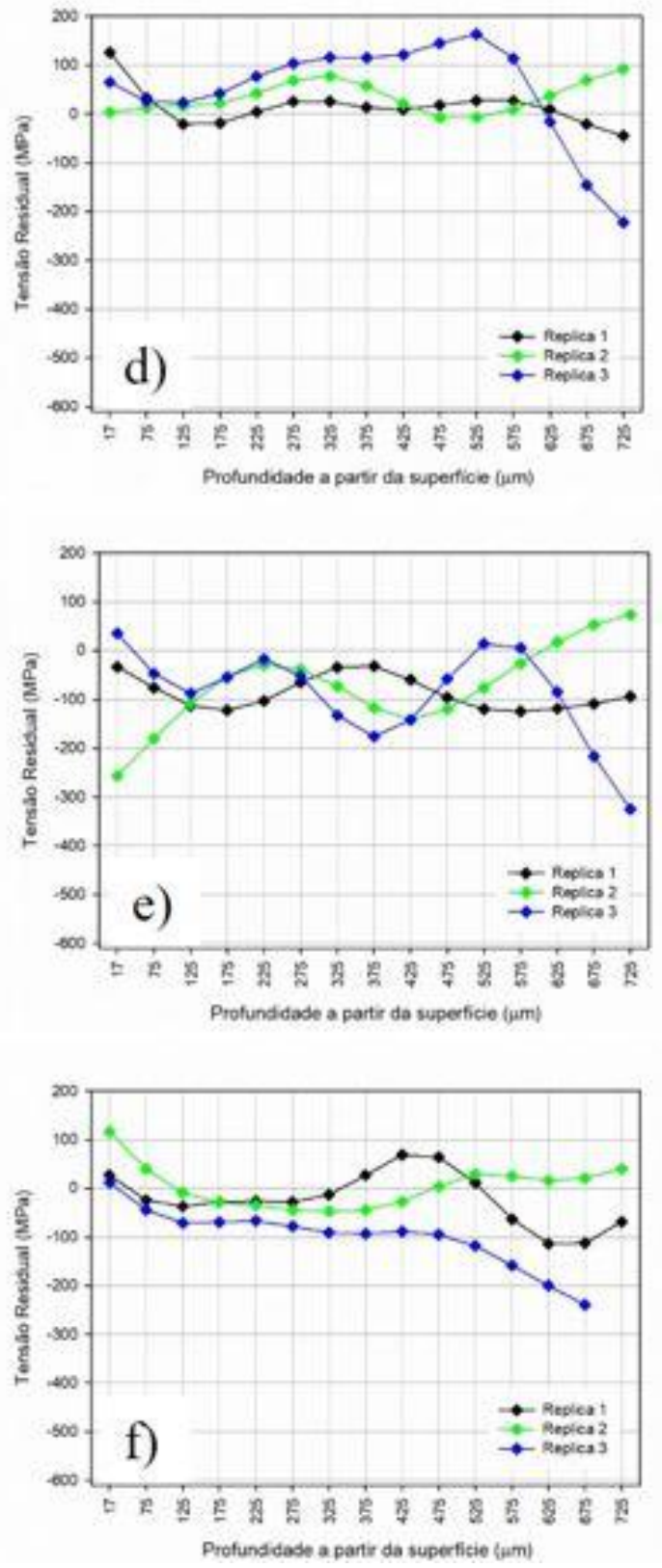

Figura 16: Perfil das tensões residuais perpendiculares à direção de avanço para $V_{c}=275 \mathrm{~m} / \mathrm{min}$ agrupadas pelo tratamento térmico e ângulo de posição da fresa para cada réplica realizada.

Tomando como base a observação das Figuras 15 e 16, optou-se pelo descarte de uma das réplicas. O resultado da aplicação desta opção está resumido no Quadro 1.

\begin{tabular}{|c|c|c|c|c|}
\hline \multirow[b]{2}{*}{ Condição } & \multicolumn{3}{|c|}{ Réplicas } & \multirow{2}{*}{$\begin{array}{c}\text { Réplicas Consideradas } \\
\text { para Análise }\end{array}$} \\
\hline & 1 & 2 & 3 & \\
\hline $100 \mathrm{~N} 12$ & & & & $1 \mathrm{e} 3$ \\
\hline $100 \mathrm{~N} 45$ & & & & $2 \mathrm{e} 3$ \\
\hline $100 \mathrm{~N} 90$ & & & & $1 \mathrm{e} 3$ \\
\hline 100R12 & & & & $2 \mathrm{e} 3$ \\
\hline $100 \mathrm{R} 45$ & & & & $2 \mathrm{e} 3$ \\
\hline 100R90 & & & & $1 \mathrm{e} 2$ \\
\hline $275 N 12$ & & & & $1 \mathrm{e} 2$ \\
\hline $275 \mathrm{~N} 45$ & & & & $1 \mathrm{e} 3$ \\
\hline 275N90 & & & & $1 \mathrm{e} 2$ \\
\hline 275R12 & & & & $1 \mathrm{e} 3$ \\
\hline 275R45 & & & & $1 \mathrm{e} 3$ \\
\hline 275R90 & & & & $1 \mathrm{e} 2$ \\
\hline
\end{tabular}

Quadro 1: Réplicas consideradas para análise 
Com base nesta seleção, foram elaborados gráficos com os respectivos perfis de tensão residual ao longo da profundidade a partir da superfície considerando a média das réplicas consideradas para análise. O resultado deste trabalho é apresentado nas Figuras 17 e 18, figuras estas similares as Figuras 15 e 16 quanto ao formato apresentado.

Normalizado
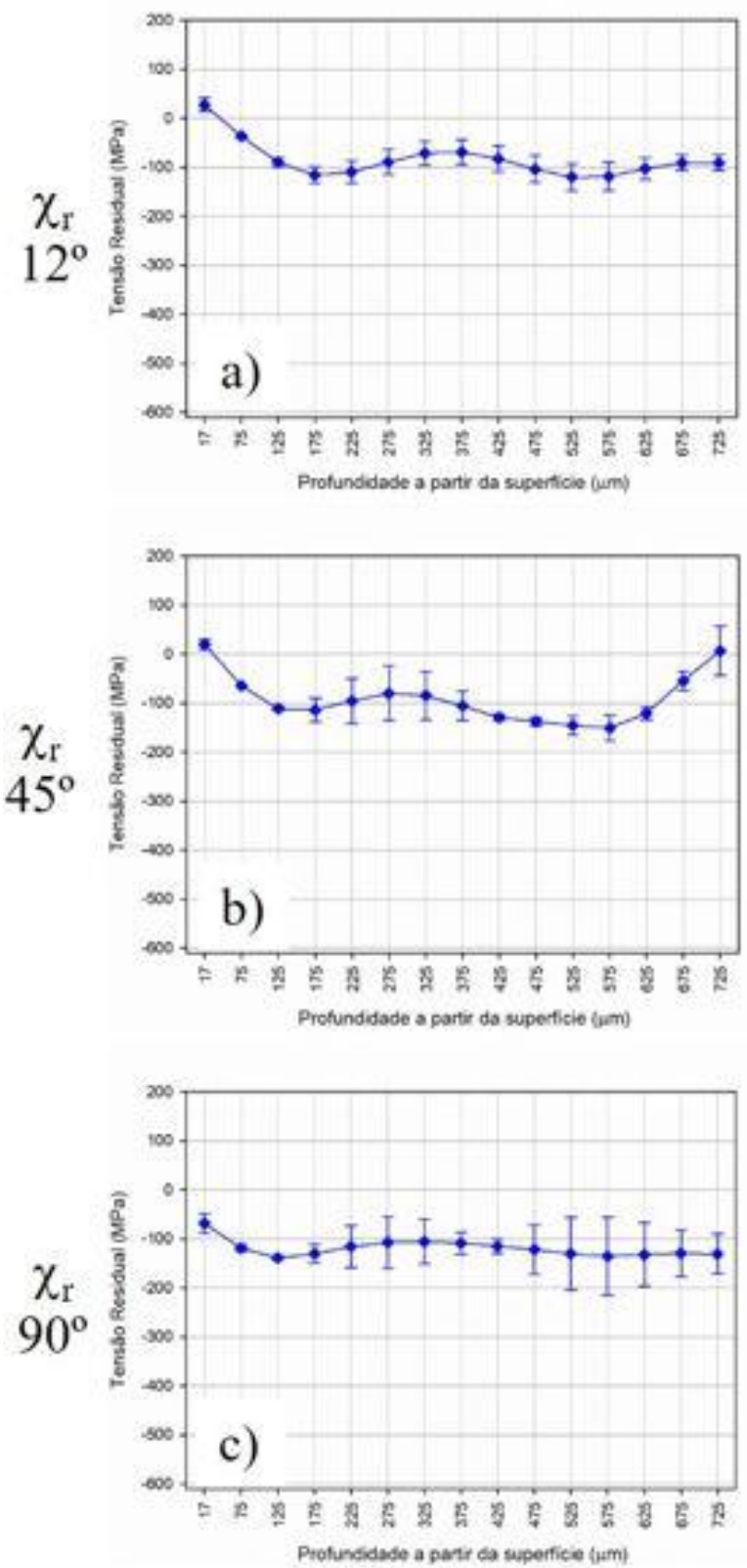

Recozido
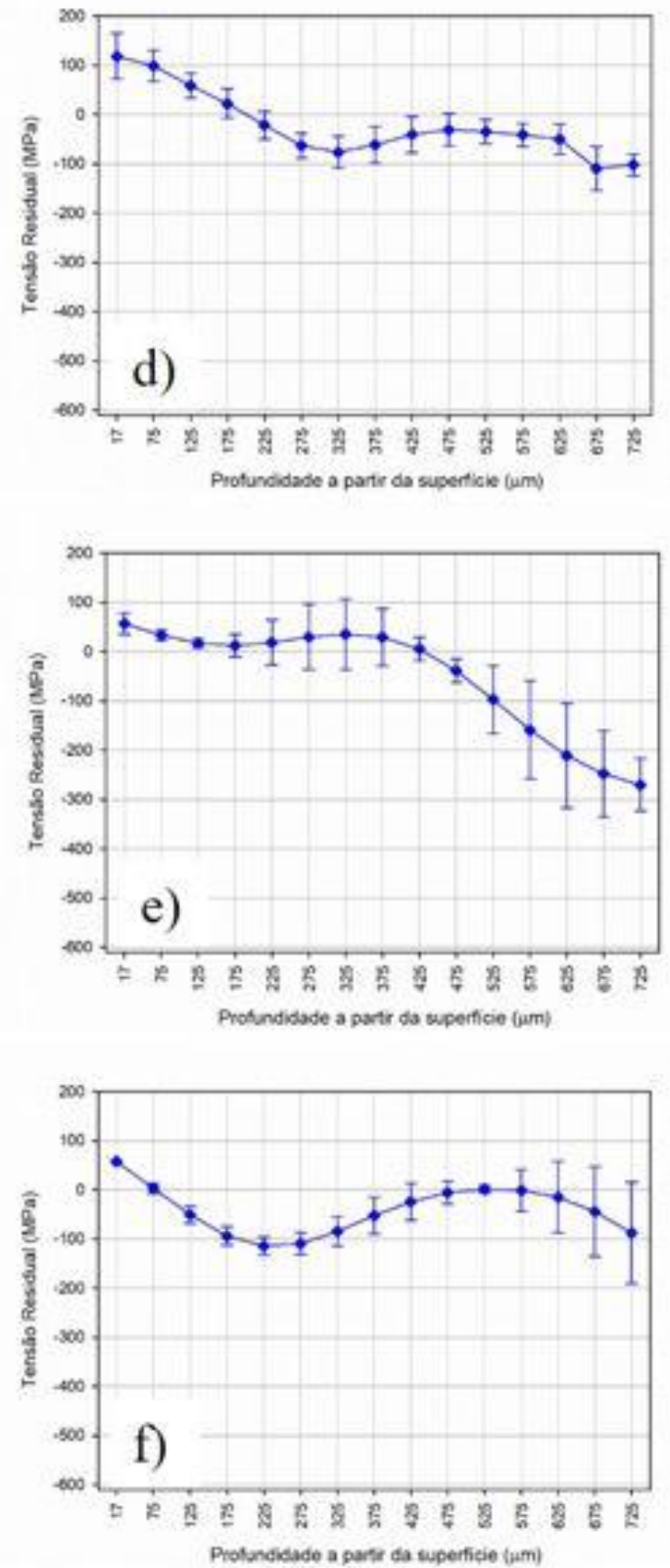

Figura 17: Perfil das tensões residuais perpendiculares à direção de avanço para $V c=100 \mathrm{~m} / \mathrm{min}$ agrupadas pelo tratamento térmico e ângulo de posição da fresa obtido pela média entre réplicas conforme Quadro 1 
Normalizado
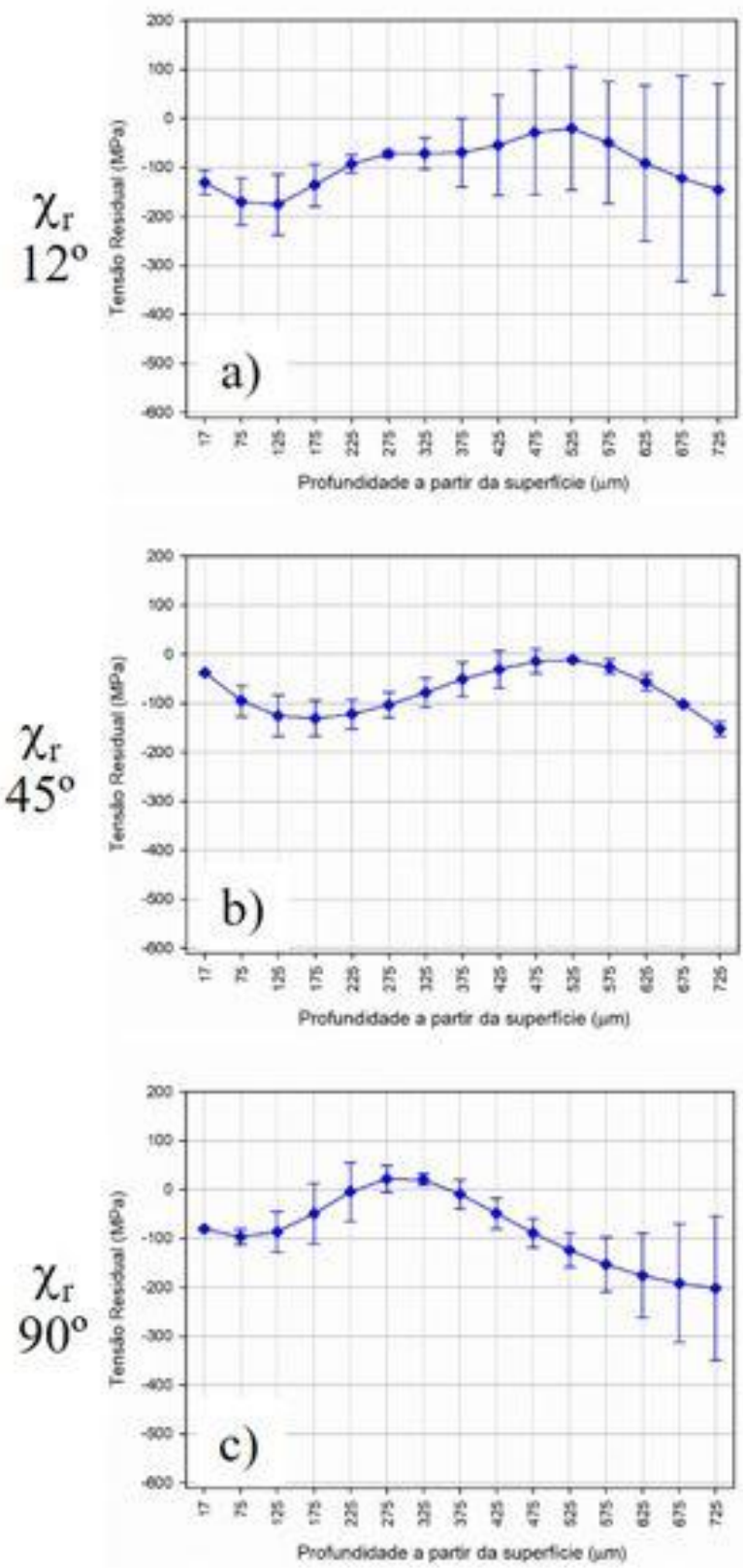

Recozido
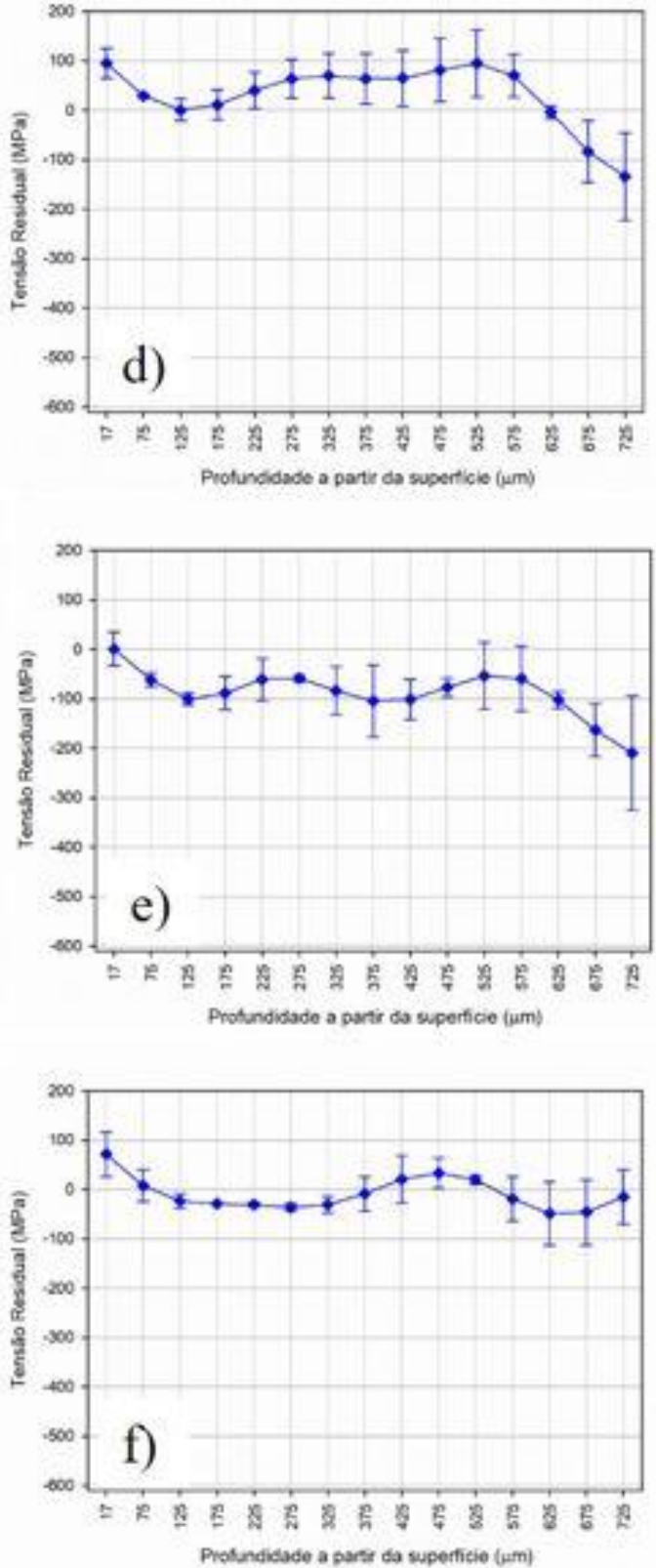

Figura 18: Perfil das tensões residuais perpendiculares à direção de avanço para $\mathrm{Vc}=275 \mathrm{~m} / \mathrm{min}$ agrupadas pelo tratamento térmico e ângulo de posição da fresa obtido pela média entre réplicas conforme Quadro 5.1

A primeira observação que pode ser feita com base nas Figuras 17 e 18 é que para todas as condições o perfil resultante apresenta erro padrão significativo ponto a ponto ao longo da profundidade a partir da superfície.

\subsection{Efeito do ângulo de posição da fresa sobre a tensão residual induzida}

Na Figura 19 pode ser observado de forma agrupada o comportamento da tensão residual perpendicular à direção de avanço ao longo da profundidade a partir da superfície quando são mantidos constantes a velocidade de corte em 100m/min, Figura 19 a) e c) e 275m/min Figura 19 b) e d), bem como a condição quanto ao tratamento térmico em normalizado, Figura 19 a), b) e recozido, Figura 19 c) e d) enquanto o ângulo de posição é variado nos três níveis. 


\section{$\mathrm{V}_{\mathrm{c}}=100 \mathrm{~m} / \mathrm{min}$}
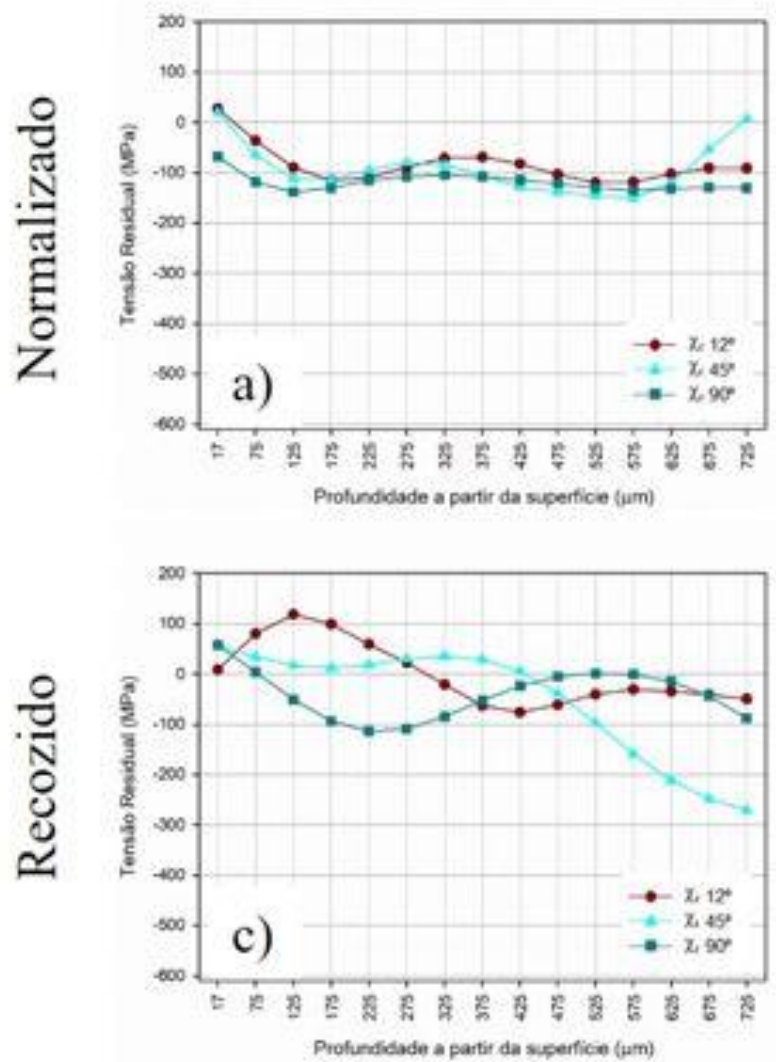

$\mathrm{V}_{\mathrm{c}}=275 \mathrm{~m} / \mathrm{min}$
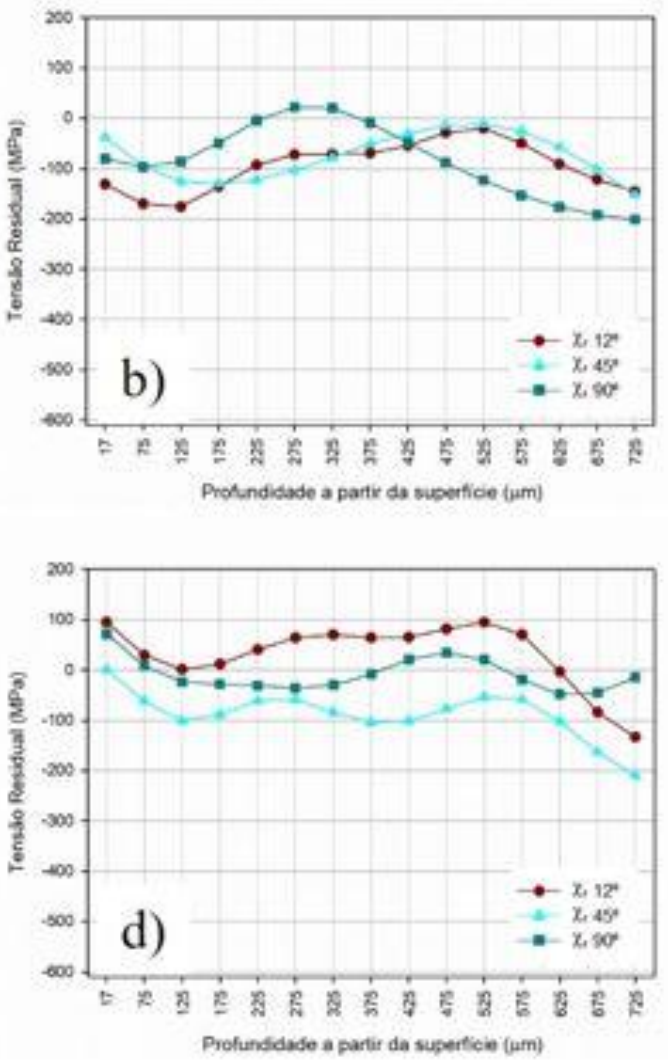

Figura 19: Resumo dos perfis de tensão residual para as condições onde são mantidos a velocidade de corte e a condição quanto ao tratamento térmico do aço, normalizado ou recozido com variação do ângulo de posição em três níveis.

Pela observação da Figura 19 pode-se inferir que para os corpos de prova, tanto na condição normalizado quanto recozido, e velocidades de corte de 100 e $275 \mathrm{~m} / \mathrm{min}$ a variação do ângulo de posição exerce pouco efeito sobre o comportamento da tensão residual. Para os ângulos de 12 e $45^{\circ}$ para a condição $100 \mathrm{~N}$ os perfis apresentam certa similaridade até a profundidade de $275 \mu \mathrm{m}$. Para as demais condições o perfil se mostra distinto para cada ângulo de posição. O Quadro 2 resume os resultados ora apresentados. O termo profundidade afetada se refere à profundidade a partir da superfície em que conforme a tendência observada alcança-se a maior intensidade de tensão residual de tração ou compressão.

\begin{tabular}{|c|c|c|c|c|c|}
\hline Condição & $\begin{array}{l}\chi_{\mathrm{r}} \\
\left({ }^{\circ}\right)\end{array}$ & \begin{tabular}{|c|} 
Caráter na \\
Superficie \\
T - Trativo \\
C - Compressivo \\
\end{tabular} & Tendência & $\begin{array}{c}\text { Profundidade } \\
\text { afetada }(\mu \mathrm{m})\end{array}$ & Resumo \\
\hline \multirow{3}{*}{$100 \mathrm{NXX}$} & 12 & $\mathrm{~T}$ & $\mathrm{C}$ & 175 & \multirow{3}{*}{$\begin{array}{l}\text { Somente quando } \chi_{\mathrm{s}} \text { passa a } 90^{\circ} \text { que se percebe } \\
\text { efeito }(\mathrm{O} \text { caráter muda de } \mathrm{T} \rightarrow \mathrm{C})\end{array}$} \\
\hline & 45 & $\mathrm{~T}$ & $\mathrm{C}$ & 175 & \\
\hline & 90 & $\mathrm{C}$ & $\mathrm{C}$ & 175 & \\
\hline \multirow{3}{*}{$100 \mathrm{RXX}$} & 12 & - & $\mathrm{T}$ & 125 & \multirow{3}{*}{$\begin{array}{l}\text { Percebe-se que aumentando } \chi_{\mathrm{s}} \text { tende-se a reduzir o } \\
\text { carater } \mathrm{T} \text { ou inverter para C } \\
\text { Ocorre inversão de tendência e a profundidade } \\
\text { afetada aumenta com o aumento de } \chi_{\mathrm{s}}\end{array}$} \\
\hline & 45 & $\mathrm{~T}$ & $\downarrow_{\mathrm{T}}$ & 175 & \\
\hline & 90 & $\mathrm{~T}$ & C & 225 & \\
\hline \multirow{3}{*}{$275 \mathrm{NXX}$} & 12 & $\mathrm{C}$ & $\mathrm{C}$ & 125 & \multirow{3}{*}{$\begin{array}{c}\text { Aumentando } \chi_{\mathrm{r}} \text { de } 12 \rightarrow 45 \text { reduz a C e } 45 \rightarrow 90 \\
\text { aumenta a C }\end{array}$} \\
\hline & 45 & C & C & 175 & \\
\hline & 90 & C & $\mathrm{T}$ & 275 & \\
\hline \multirow{3}{*}{$275 R X X$} & 12 & $\mathrm{~T}$ & $\downarrow T$ & 125 & \multirow{3}{*}{$\begin{array}{c}\text { Aumentando } \chi_{\mathrm{s}} \text { de } 12 \rightarrow 45 \text { reduz a T e } 45 \rightarrow 90 \\
\text { aumenta a } \mathrm{T}\end{array}$} \\
\hline & 45 & - & $\mathrm{C}$ & 125 & \\
\hline & 90 & $\mathrm{~T}$ & $\mathrm{C}$ & 175 & \\
\hline
\end{tabular}

Quadro 2: Resumo - efeito do ângulo de posição da fresa sobre a tensão residual induzida 


\subsection{Efeito da velocidade de corte sobre a tensão residual induzida}

Na Figura 20 pode ser observado de forma agrupada o comportamento da tensão residual perpendicular à direção de avanço ao longo da profundidade a partir da superfície quando são mantidos constantes o ângulo de posição em $12^{\circ}$, Figura 20 a) e d), $45^{\circ}$ Figura 20 b) e e), $90^{\circ}$ Figura 20 c) e f) bem como a condição, quanto ao tratamento térmico do aço, normalizado, Figura 20 a), b) e c), e recozido, Figura 20 d), e) e f) para a velocidade de corte variando em dois níveis, 100 e $275 \mathrm{~m} / \mathrm{min}$.

Normalizado
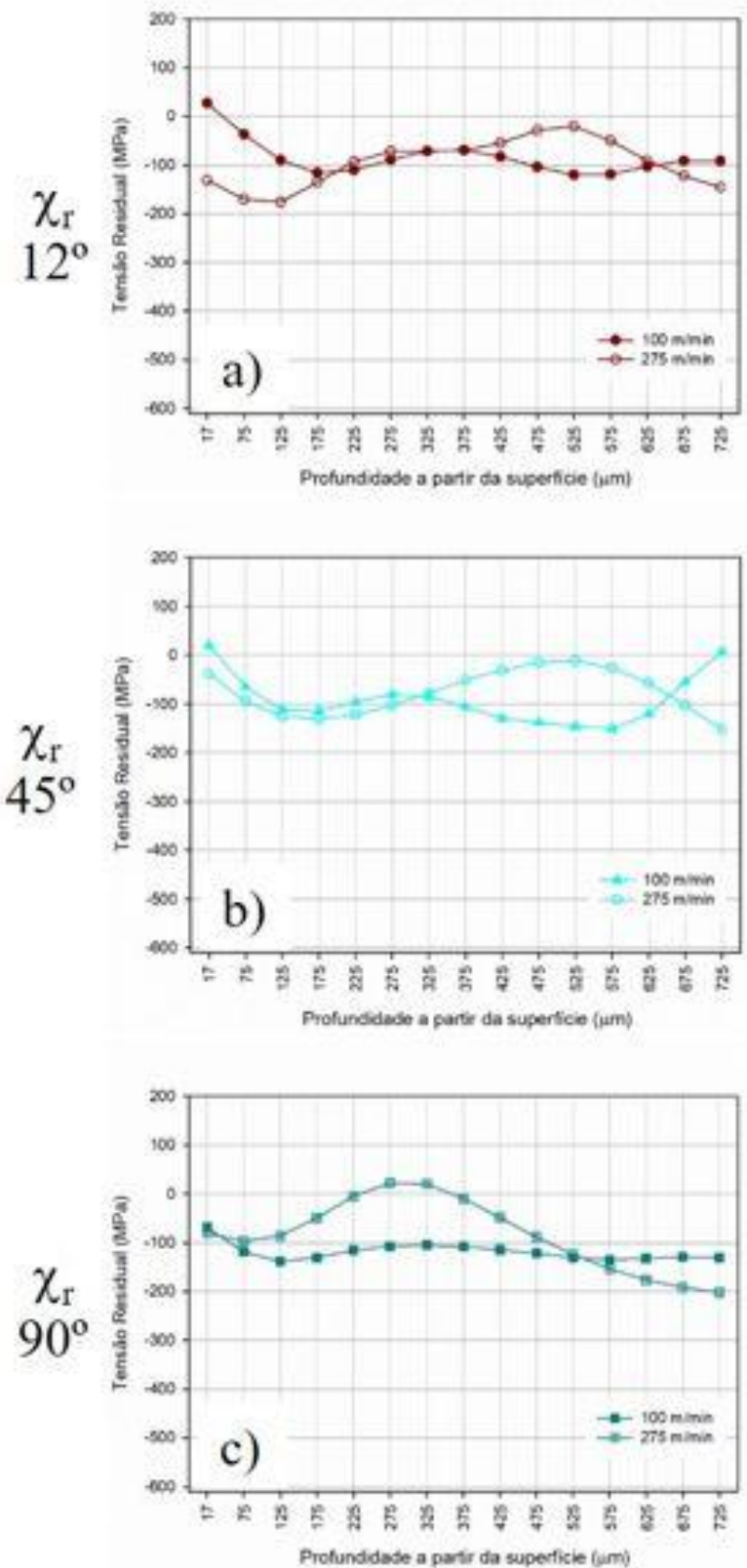

Recozido
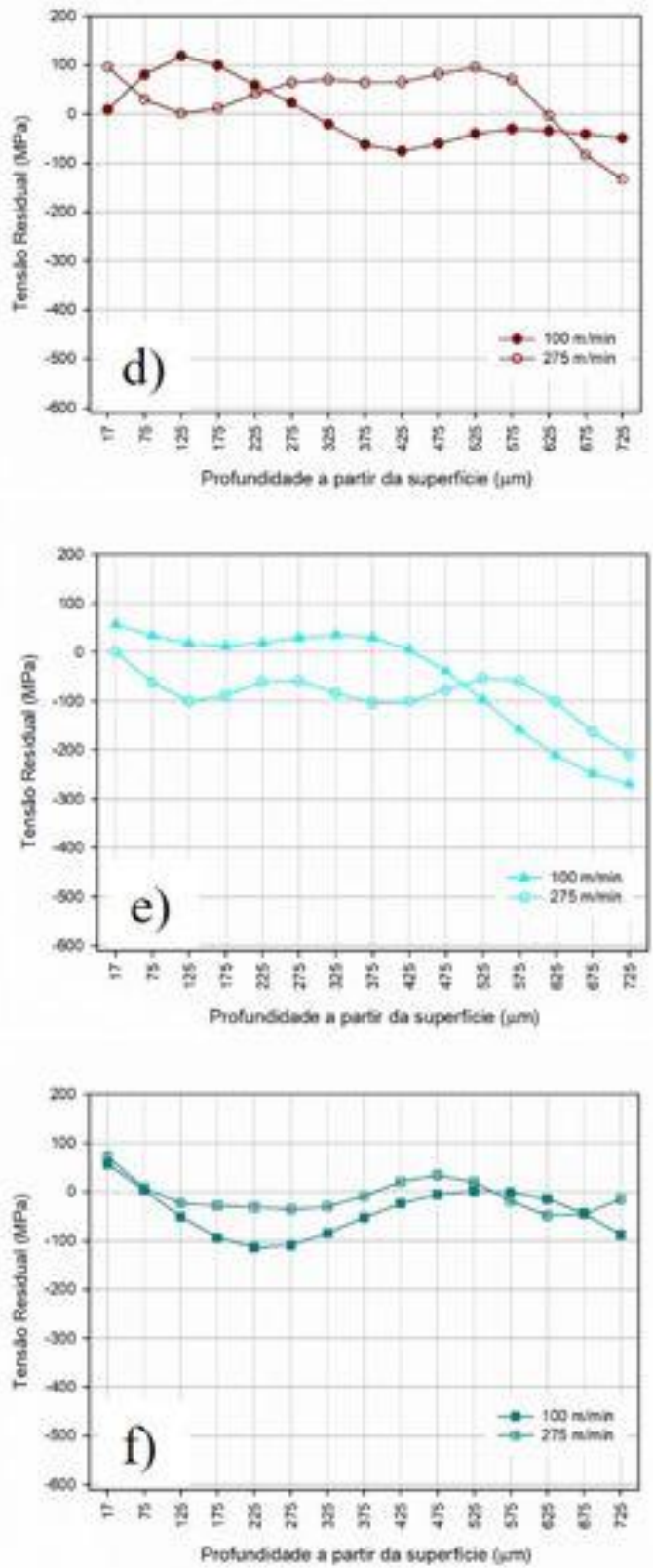

Figura 20: Resumo dos perfis de tensão residual para as condições onde são mantidos o ângulo de posição e a condição quanto ao tratamento térmico do aço, normalizado ou recozido com variação da velocidade de corte em dois níveis.

Pela observação da Figura 20 pode-se inferir que para os corpos de prova, tanto na condição normalizado quanto recozido, o aumento da velocidade de corte exerce influência similar na tensão residual quando este é fresado com fresa com ângulo deposição de 12 e $45^{\circ}$, ou seja, tornam o perfil de tensões residuais ao longo da profundidade a partir da superfície mais compressivo. Para $12^{\circ}$, Figura 20 a), mais pronunciado próximo à superfície fresada e $45^{\circ}$, Figura 20 b), de forma mais discreta. Quando o corpo de prova é fresado com 
fresa com ângulo de posição de $90^{\circ}$, Figura 20 c), ocorre de forma contraria, visto que para este caso o aumento da velocidade de corte torna o perfil mais trativo ou menos compressivo, Figura 20 f). O Quadro 3 resume os resultados ora apresentados. O termo profundidade afetada se refere à profundidade a partir da superfície em que conforme a tendência observada alcança-se a maior intensidade de tensão residual de tração ou compressão.

\begin{tabular}{|c|c|c|c|c|c|}
\hline Condição & $\begin{array}{c}\mathrm{V}_{\mathrm{c}} \\
(\mathrm{m} / \mathrm{min})\end{array}$ & \begin{tabular}{|c|} 
Caráter na \\
Superficie \\
T - Trativo \\
C - Compressivo \\
\end{tabular} & Tendência & $\begin{array}{c}\text { Profundidade } \\
\text { afetada }(\mu \mathrm{m})\end{array}$ & Resumo \\
\hline \multirow{2}{*}{ AAAN12 } & 100 & $\mathrm{~T}$ & $\mathrm{C}$ & 175 & \multirow{2}{*}{ Aumento de $\mathrm{V}_{\mathrm{c}}$ torna o caráter $\mathrm{C}$} \\
\hline & 275 & $\mathrm{C}$ & $\mathrm{C}$ & 125 & \\
\hline \multirow{2}{*}{ AAAR12 } & 100 & - & $\mathrm{T}$ & 125 & \multirow{2}{*}{ Aumento de $\mathrm{V}_{\mathrm{c}}$ reduz o caráter $\mathrm{T}$} \\
\hline & 275 & $\mathrm{~T}$ & $\mathrm{C}$ & 125 & \\
\hline \multirow{2}{*}{ AAAN45 } & 100 & $\mathrm{~T}$ & $\mathrm{C}$ & 175 & \multirow{2}{*}{$\begin{array}{l}\text { Aumento de } \mathrm{V}_{\mathrm{c}} \text { torna o caráter discretamente mais } \\
\qquad \mathrm{C}\end{array}$} \\
\hline & 275 & $\mathrm{C}$ & $\mathrm{C}$ & 175 & \\
\hline \multirow{2}{*}{ AAAR 45 } & 100 & $\mathrm{~T}$ & $\downarrow \mathrm{T}$ & 175 & \multirow{2}{*}{ Aumento de $\mathrm{V}_{\mathrm{c}}$ torna o caráter $\mathrm{C}$} \\
\hline & 275 & - & $\mathrm{C}$ & 125 & \\
\hline \multirow{2}{*}{ AAAN90 } & 100 & $\mathrm{C}$ & $\mathrm{C}$ & 125 & \multirow{2}{*}{$\begin{array}{c}\text { Aumento de } V_{c} \text { faz com que a tendência seja de } \mathrm{T} \\
\text { e aumenta a profundidade afetada }\end{array}$} \\
\hline & 275 & $\mathrm{C}$ & $\mathrm{T}$ & 275 & \\
\hline \multirow{2}{*}{ AAAR90 } & 100 & $\mathrm{~T}$ & $\mathrm{C}$ & 225 & \multirow{2}{*}{ Aumetno de $V_{c}$ reduz a profundidade afetada } \\
\hline & 275 & $\mathrm{~T}$ & C & 175 & \\
\hline
\end{tabular}

Quadro 3: Resumo - efeito da velocidade de corte sobre a tensão residual induzida

\section{5 Efeito da condição quanto ao tratamento térmico, normalizado ou recozido, sobre a tensão resi- dual induzida}

Na Figura 21 pode ser observado de forma agrupada o comportamento da tensão residual perpendicular à direção de avanço ao longo da profundidade a partir da superfície quando são mantidos constantes o ângulo de posição em $12^{\circ}$, Figura 21 a) e d), $45^{\circ}$ Figura 21 b) e e), $90^{\circ}$ Figura 21 c) e f), bem como a velocidade de corte em 100m/min, Figura 21 a), b) e c), e 275m/min, Figura 21 d), e) e f) para a condição quanto a tratamento térmico variando nos dois níveis, recozido e normalizado. 


\section{$\mathrm{V}_{\mathrm{c}}=100 \mathrm{~m} / \mathrm{min}$}
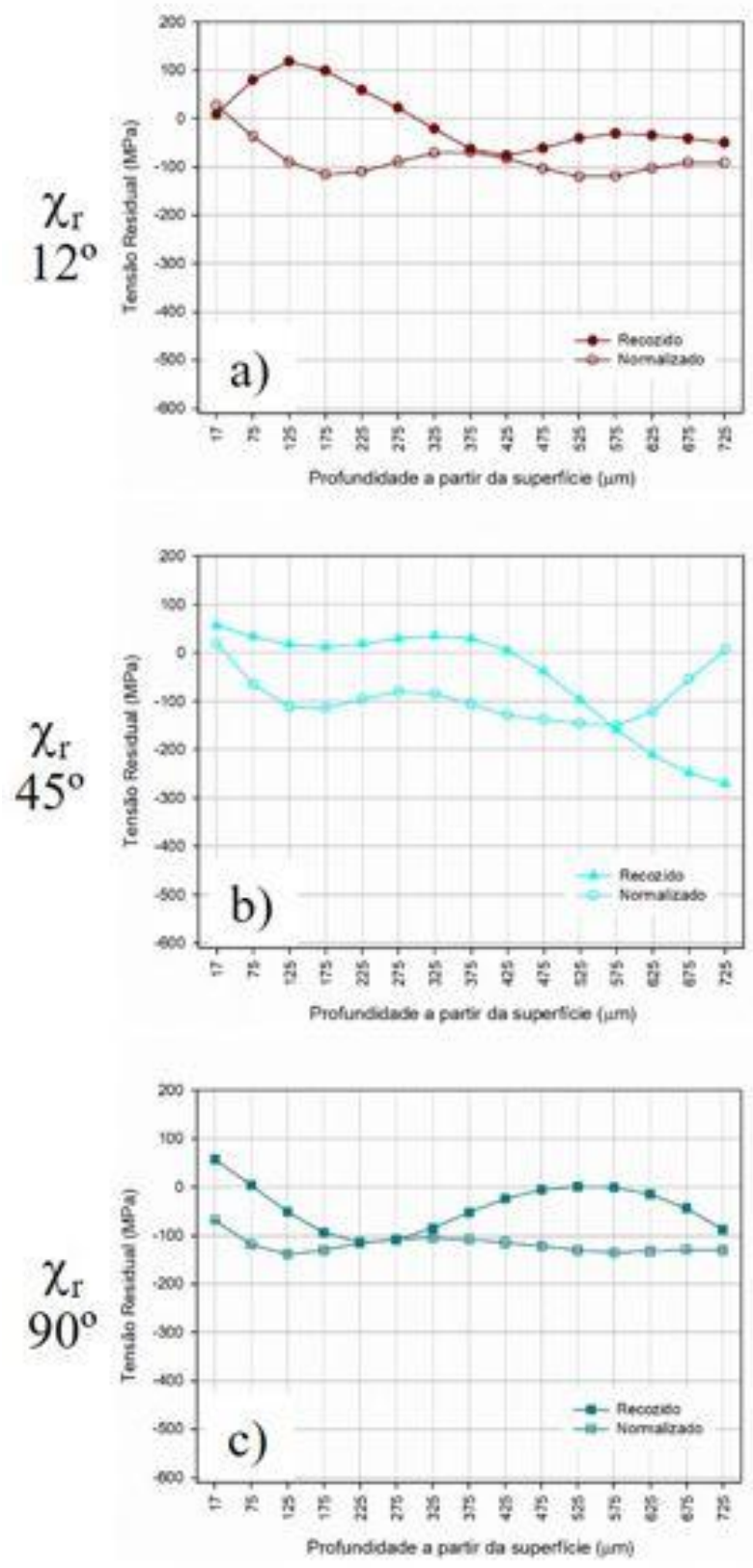

$\mathrm{V}_{\mathrm{c}}=275 \mathrm{~m} / \mathrm{min}$
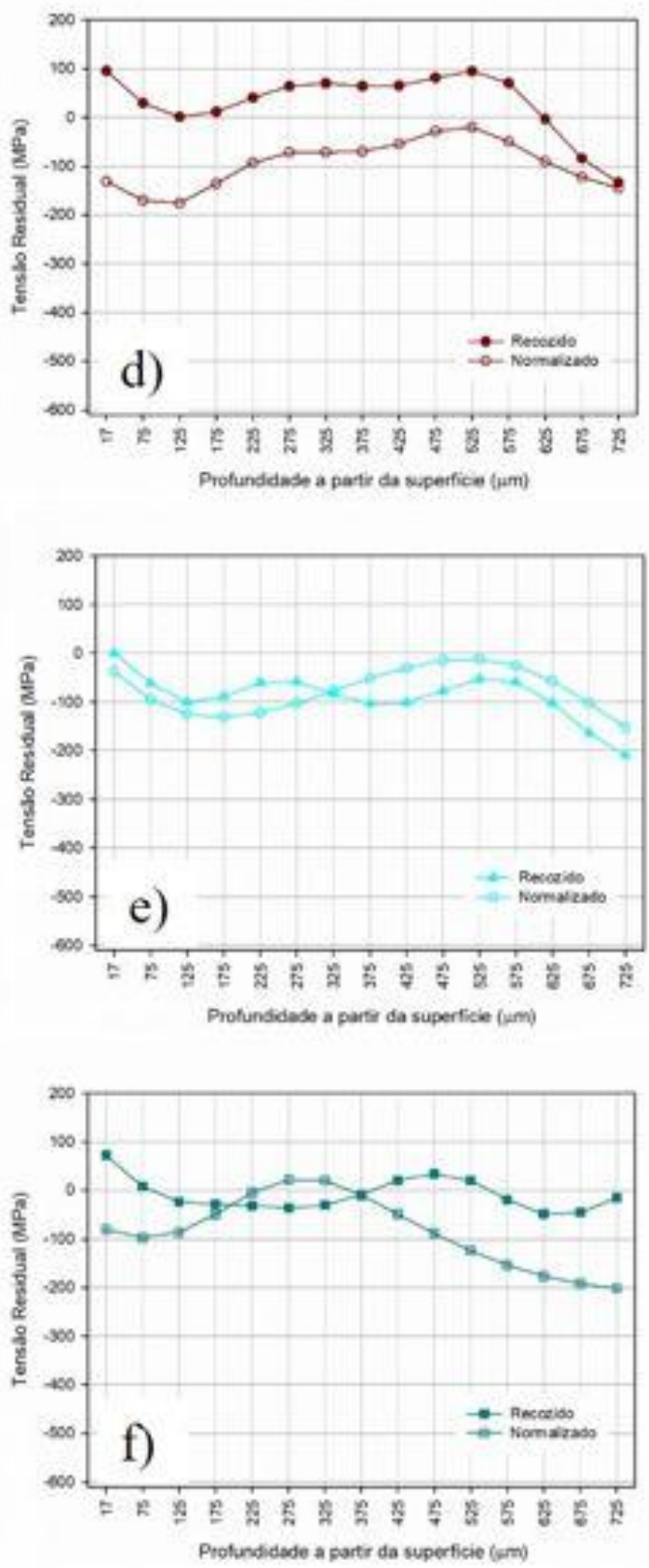

Figura 21: Resumo dos perfis de tensão residual para as condições onde são mantidos o ângulo de posição e a velocidade de corte com variação da condição quanto ao tratamento térmico do aço em dois níveis.

Pela observação da Figura 21 pode-se inferir que para os corpos de prova, tanto para a velocidade de corte em seu nível inferior quanto superior, a condição quanto ao tratamento térmico exerce influência similar na tensão residual quando este é fresado com fresa com ângulo de posição de 12,45 e $90^{\circ}$, ou seja, a condição normalizada torna o caráter e o perfil de tensões residuais ao longo da profundidade a partir da superfície compressivo. Quanto à tendência, apenas as condições 100R12 e 275N90 apresentam comportamento distinto das demais, tornar-se trativa. A menor diferença entre as tensões residuais para as duas condições, recozida e normalizada, é observada na condição 275B45, Figura 21 b), e a maior na 275B12, Figura 21 d). O Quadro 4 resume os resultados ora apresentados. O termo profundidade afetada se refere à profundidade a partir da superfície em que conforme a tendência observada alcança-se a maior intensidade de tensão residual de tração ou compressão. 


\begin{tabular}{|c|c|c|c|c|c|}
\hline Condição & \begin{tabular}{|c} 
Tratamento \\
Térmico \\
N - Normalizado \\
R - Recozido \\
\end{tabular} & $\begin{array}{c}\text { Caráter na } \\
\text { Superficie } \\
\text { T - Trativo } \\
\text { C - Compressivo }\end{array}$ & Tendência & $\begin{array}{r}\text { Profundidade } \\
\text { afetada }(\mu \mathrm{m})\end{array}$ & Resumo \\
\hline \multirow{2}{*}{ 100B12 } & $\mathbf{N}$ & $\mathrm{T}$ & $\mathrm{C}$ & 175 & \multirow{2}{*}{$\begin{array}{c}\text { A variação de } \mathrm{R} \rightarrow \mathrm{N} \text { faz com que a tendência se } \\
\text { torne } \mathrm{C}\end{array}$} \\
\hline & $\mathbf{R}$ & - & $\mathrm{T}$ & 125 & \\
\hline \multirow{2}{*}{ 100B45 } & $\mathbf{N}$ & $\mathrm{T}$ & $\mathrm{C}$ & 175 & \multirow{2}{*}{$\begin{array}{c}\text { A variação de } \mathrm{R} \rightarrow \mathrm{N} \text { faz com que o caráter se } \\
\text { torne } \mathrm{C}\end{array}$} \\
\hline & $\mathbf{R}$ & $\mathrm{T}$ & $\downarrow_{\mathrm{T}}$ & 175 & \\
\hline \multirow{2}{*}{ 100B90 } & $\mathbf{N}$ & $\mathrm{C}$ & $\uparrow \mathrm{C}$ & 125 & \multirow{2}{*}{$\begin{array}{l}\text { A variação de } \mathrm{R} \rightarrow \mathrm{N} \text { faz com que o caráter se } \\
\text { torne } \mathrm{C} \text { e aumenta a profundiade afeta }\end{array}$} \\
\hline & $\mathbf{R}$ & $\mathrm{T}$ & $\mathrm{C}$ & 225 & \\
\hline \multirow{2}{*}{ 275B12 } & $\mathbf{N}$ & $\mathrm{C}$ & $\uparrow \mathrm{C}$ & 125 & \multirow{2}{*}{$\begin{array}{c}\text { A variação de } \mathrm{R} \rightarrow \mathrm{N} \text { faz com que o caráter se } \\
\text { torne } \mathrm{C}\end{array}$} \\
\hline & $\mathbf{R}$ & $\mathrm{T}$ & $\downarrow_{\mathrm{T}}$ & 125 & \\
\hline \multirow{2}{*}{ 275B45 } & $\mathbf{N}$ & $\mathrm{C}$ & $\uparrow \mathrm{C}$ & 175 & \multirow{2}{*}{$\begin{array}{l}\text { A variação de } \mathrm{R} \rightarrow \mathrm{N} \text { produz efeito muito discreto, } \\
\text { sendo o caráter do normalizado mais } \mathrm{C}\end{array}$} \\
\hline & $\mathbf{R}$ & - & $\mathrm{C}$ & 125 & \\
\hline \multirow{2}{*}{ 275B90 } & $\mathrm{N}$ & $\mathrm{C}$ & $\mathrm{T}$ & 275 & \multirow{2}{*}{$\begin{array}{l}\text { A variação de } \mathrm{R} \rightarrow \mathrm{N} \text { faz com que o caráter se } \\
\text { torne } \mathrm{C} \text {, porém com tendência a } \mathrm{T}\end{array}$} \\
\hline & $\mathbf{R}$ & $\mathrm{T}$ & $\mathrm{C}$ & 225 & \\
\hline
\end{tabular}

Quadro 4: Resumo - efeito da condição quanto a tratamento térmico, recozido ou normalizado, sobre a tensão residual induzida.

\section{CONCLUSÕES}

A variação da velocidade de corte exerceu efeito sobre a tensão residual. Com o aumento da velocidade de corte o caráter da tensão residual se tornou compressivo ou menos trativo. Também foi observado variação na intensidade da tensão residual na profundidade de $17 \mu \mathrm{m}$ a partir da superfície.

A variação do ângulo de posição exerceu efeito discreto sobre o caráter trativo ou compressivo da tensão residual bem como sobre a intensidade na profundidade de $17 \mu \mathrm{m}$.

A variação da condição do material quanto ao tratamento térmico de recozido para normalizado exerceu o efeito de tornar o caráter da tensão residual compressivo.

Não foi observada nenhuma tendência obvia ao tentar-se estabelecer alguma relação entre a força de usinagem e a tensão residual.

\section{AGRADECIMENTOS}

O presente trabalho foi realizado com apoio do Programa de Pós-Graduação em Engenharia Mecânica da Universidade Federal de Minas Gerais.

\section{BIBLIOGRAFIA}

[1] MACHADO, Á. R., et al., Teoria da Usinagem dos Materiais, $3^{\mathrm{a}}$ ed., São Paulo, Blucher, 2015.

[2] VISHAY PRECISION GROUP, Instruction Bulletin B-129-8, Surface Preparation for Strain Gage Bonding, n. 11129, p. 1-7, 2011.

[3] TRENT, E. M., WRIGHT, P. K., Metal Cutting, 4a ed., Woburn, Butterworth-Heinemann, 2000.

[4] CHIAVERINI, V., Aços e ferros fundidos, São Paulo, ABM (Associação Brasileira de Metalurgia e Materiais), 1996.

[5] ANAZAWA, R., et al., "Caracterização microestrutural e mecânica dos aços 4340 e 300m após tratamentos térmicos isotérmicos e intercríticos" Faculdade de Engenharia -Universidade Estadual PaulistaFEG/UNESP, Guaratinguetá - SP, p. 11, 2012.

[6] FREITAS, B. M., et al., "Comparativo Da Microestrutura E Da Microdureza No Aço 4340 a Diferentes Tempos De Recozimento", Congresso Técnico Cientifico da Engenharia e da Agronomia, n. 2008, p. 6, 2016.

[7] COLPAERT, H., Metalografia dos produtos siderurgicos comuns, São Paulo, Edgard Blücher, 2008.

[8] EL-KHABEERY, M. M., FATTOUH, M., "Residual stress distribution caused by milling", International Journal of Machine Tools and Manufacture, v. 29, n. 3, pp. 339-401, 1989. 
[9] SU, J. C., Residual Stress Modeling in Machining Processes, PhD Thesis in Mechanical Engineering, Georgia Institute of Technology, n. December, p. 186, 2006.

[10] HENRIKSEN, E. K., "Residual Stresses in Machined Surfaces", American Society of Mechanical Engineers, v. 73, n. 1, p. 69-76, 1951.

[11] LIU, C. R., BARASH, M. M., "Variables Governing Patterns of Mechanical Residual Stress in a Machined Surface", Journal of Engineering for Industry, Transactions ASME, v. 104, n. 3, pp. 257-264, 1982.

[12] XIE, Q., et al., "Study on Residual Stresses and Tool Wear Induced by the Machining Process", in NAMRC XVII, v. SSME, 1989.

[13] SADAT, A. B., BAILEY, J. A., "Residual stresses in turned AISI 4340 steel”, Experimental Mechanics, v. 27 , n. 1 , p. $80-85,1987$ b.

[14] TOTTEN, G., HOWES, M., INOUE, T., Handbook of Residual Stress and Deformation of Steel, Novelty, ed. Ohio, ASM International, 2002.

[15] ASTM E837, S., Determining residual stresses by the hole-drilling strain-gage method, ASTM, 2013.

[16] ANDEROGLU, O., "Residual stress measurement using X-ray diffraction, Texas A\&M University, 2005

[17] SCHAJER, G. S., Practical Residual Stress Measurement Methods, 2013. ed Columbia, Wiley e Sons, 2013.

[18] NAVAS, V. G., GONZALO, O., BENGOETXEA, I., "Effect of cutting parameters in the surface residual stresses generated by turning in AISI 4340 steel", International Journal of Machine Tools and Manufacture, v. 61, pp. 48-57, 2012.

[19] HUANG, Q., XIN, J. J., "Surface Intergity and Its Effects on the Fatigue Life on Nickel Based Superalloy GH33A”, International Journal of Fatigue, v. 13, n. 4, p. 4, 1991

[20] MANTLE, A. L., ASPINWALL, D. K., "Surface integrity of a high speed milled gamma titanium aluminide", Journal of Materials Processing Technology, v. 118, n. 1-3, pp. 143-150, 2001.

[21] SUN, J., GUO, Y. B., "A comprehensive experimental study on surface integrity by end milling Ti-6Al4V”, Journal of Materials Processing Technology, v. 209, n. 8, pp. 4036-4042, 2009.

[22] ZHANG, S., DING, T. C., LI, J. F., "Determination of surface and in-depth residual stress distributions induced by hard milling of H13 steel”, Production Engineering, v. 6, n. 4-5, pp. 375-383, 2012.

[23] KWONG, J., AXINTE, D. A., WITHERS, P. J., "The sensitivity of Ni-based superalloy to hole making operations: Influence of process parameters on subsurface damage and residual stress", Journal of Materials Processing Technology, v. 209, n. 8, pp. 3968-3977, 2009.

[24] SU, J. C., Residual Stress Modeling in Machining Processes, PhD Thesis in Mechanical Engineering, Georgia Institute of Technology, n. December, p. 186, 2006.

[25] JAVIDI, A., RIEGER, U., EICHLSEDER, W. "The effect of machining on the surface integrity and fatigue life", International Journal of Fatigue, v. 30, n. 10-11, pp. 2050-2055, 2008.

[26] SASAHARA, H., "The effect on fatigue life of residual stress and surface hardness resulting from different cutting conditions of $0.45 \% \mathrm{C}$ steel", International Journal of Machine Tools and Manufacture, v. 45, n. 2, pp. 131-136, 2005.

[27] ABNT 6892-1, N., Materiais etmálicos - Ensaio de Tração Parte 1: Método de ensaio à temperatura ambiente, Rio de Janeiro, Abnt, 2018.

[28] GRANT, P. V, LORD, J. D., WHITEHEAD, P., “The Measurement of Residual Stresses by the Incremental Hole Drilling Technique", Measurement Good Practice Guide, v. 53, n. 2, p. 63, 2006.

[29] PEREIRA, N. F. S., Análise comparativa do desempenho de brocas de aço rápido AISI M2 revestidas com SiO2 pelo processo de SOL-GEL na furação do frerro fundido nodular, Dissertação de Mestrado, UFMG - Universidade Federal de Minas Gerais, 2017.

[30] PEREIRA, J. C. C. Tensões residuais induzidas pela operação de fresamento dos aços ABNT $1010 e$ ABNT 4340, UFMG - Universidade Federal de Minas Gerais, 2016.

\section{ORCID}

Airton de Souza

Marcelo Araújo Câmara https://orcid.org/0000-0001-5574-0282

https://orcid.org/0000-0003-0617-9163 